\title{
INVESTIGACIONES ARQUEOLÓGICAS EN LA CUENCA DEL LAGO ROGOAGUADO, LLANOS DE MOJOS, BOLIVIA*
}

\author{
GORITUMI ECHEVARRÍA LÓPEZ \\ UNIVERSIDAD NACIONAL MAYOR DE SAN MARCOS \\ goritumi@gmail.com
}

\section{RESUMEN}

El artículo trata sobre las investigaciones arqueológicas llevadas a cabo en el lago Rogoaguado, provincia de Yacuma, en los Llanos de Mojos de Bolivia. Para esto se hace un panorama geográfico y arqueológico de la región, el que sirve de base y antecedente a los propios datos de las excavaciones conducidas por el autor en la zona el año 2006.

La información que se expone se circunscribe fundamentalmente a uno de los cuatro pozos de excavación realizados en las márgenes del lago, en el sitio llamado el Paquió, que consistió en un montículo bajo de conchas lacustres y un depósito extenso de cerámica y otros materiales muebles. Esta información constituye nueva data para la arqueología de los llanos de Mojos.

Palabras Clave: Bolivia, Llanos de Mojos, Rogoaguado, montículos de conchas.

\section{AbSTRACT}

The present paper describes the archaeological research carried out in the Rogoaguado Lake, located in the province of Yacuma, Llanos de Mojos, in Bolivia. A geographical and archaeological background of the region is presented which serves as a base and antecedent to the data resulted of the excavations conducted by the author in the area in 2006.

The Information exposed here is mainly restricted to one of the four excavation zones located in the banks of the Lake, in a site called El Paquió, which consisted of a low mound of shells form the lake and an extensive deposit of ceramic and other materials. This information is new data for the archaeology of the Llanos de Mojos.

KeYwords: Bolivia, Llanos de Mojos, Rogoaguado, shell mounds.

* Este artículo se presentó como una ponencia al Congreso Internacional de Antropología Amazónica en los Países Andinos «Por donde hay soplo». llevado a cabo del 16 al 20 de noviembre del año 2009 en el Centro Cultural de la PUCP. 


\section{INTRODUCCIÓN}

El presente trabajo es una introducción general a la arqueología de los Llanos de Mojos, y en especial a la zona del lago Rogoaguado, donde el autor dirigió exploraciones y excavaciones arqueológicas el año 2006. Las investigaciones en la amazonia boliviana, circunscritas a las márgenes del lago Rogoaguado y la isla El Tesoro, se llevaron a cabo con el fin de documentar y determinar el tipo y variación de las ocupaciones culturales pretéritas existentes en la zona, siendo un estudio introductorio y una apertura al conocimiento arqueológico de la región.

Como se verá en el texto, los resultados de este trabajo mostraron un muy interesante conjunto de evidencia, que incluye materiales muebles, patrones de asentamiento y por sobre todo la determinación de los patrones de consumo de determinados productos lacustres. Los datos obtenidos, especialmente del sitio el Paquió, han permito establecer una base material primaria para la propuesta de hipótesis sobre los tipos de ocupación, relaciones sociales e implicancia histórica de esta región boliviana.

\section{LA ARQueología de los Llanos de Mojos}

Aunque ningún trabajo individual ha tratado comprensivamente sobre la historia y la arqueología de los Llanos de Mojos, es necesario, para una mejor comprensión de uno de los nichos más particulares de la arqueología amazónica Boliviana, el establecer ciertos parámetros geográficos y arqueológicos antes de la introducción de nuestros propios datos de investigación en la zona.

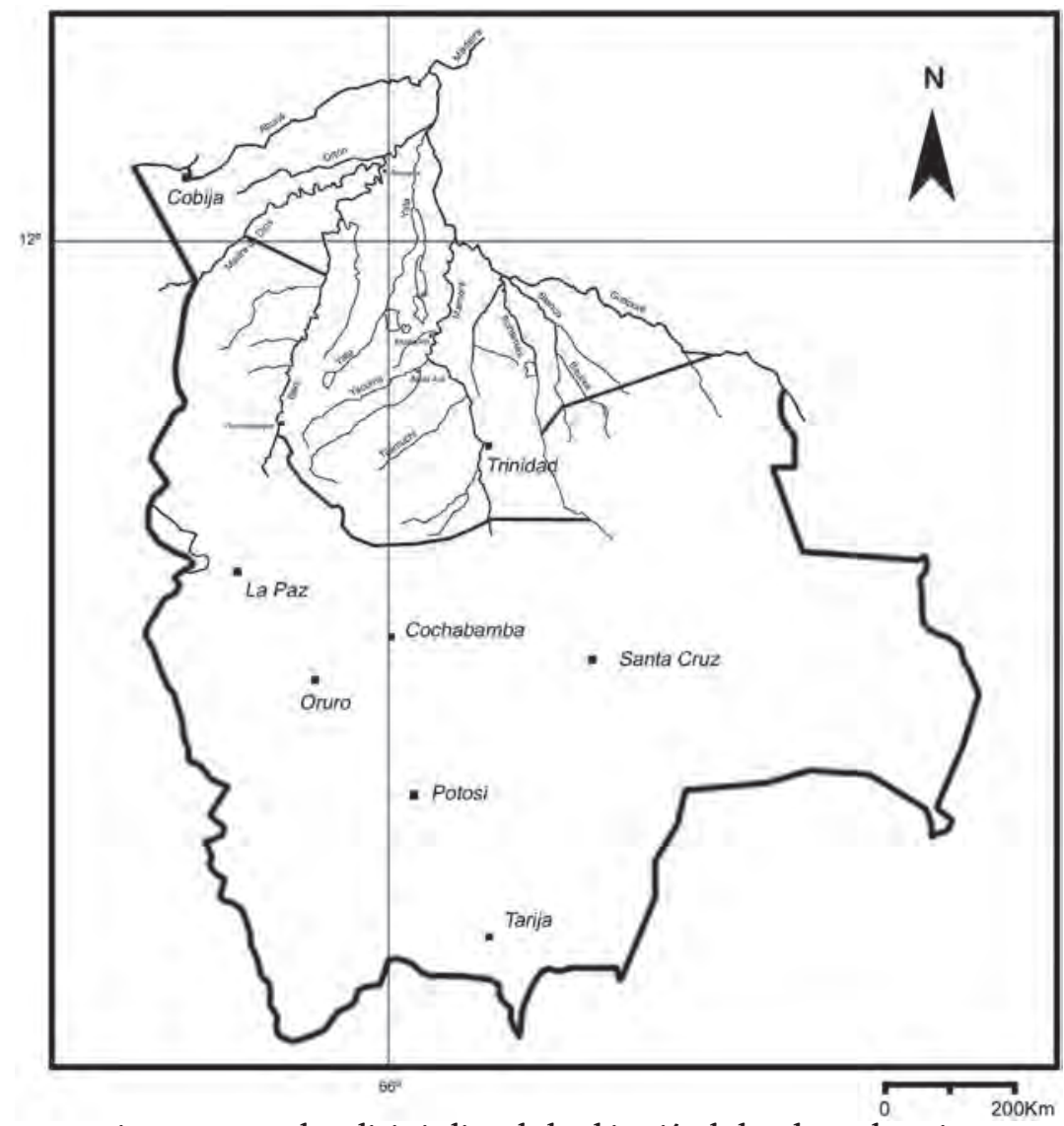

Figura 1. Mapa de Bolivia indicando la ubicación de los Llanos de Mojos. 
Llanos de Mojos es la denominación común de un área de territorio ubicado al noroeste de Bolivia cubriendo casi en su totalidad el departamento de Beni situado al norte del departamento de Cochabamba (Fig. 1). La zona está comprendida entre el río Itenez-Guaporé (que divide Bolivia y Brasil) hacia el noreste; el río Blanco, hacia el este; y las yungas fluviales andinas al suroeste; más precisamente entre los límites de la zona hylaea amazónica (zona de bosque franco) que rodean las cuencas del Beni y Mamoré, los dos principales ríos de los llanos pertenecientes a la cuenca amazónica (Fig. 2). Ecológicamente este territorio cubre una pampa de tipo sabana tropical con cubierta

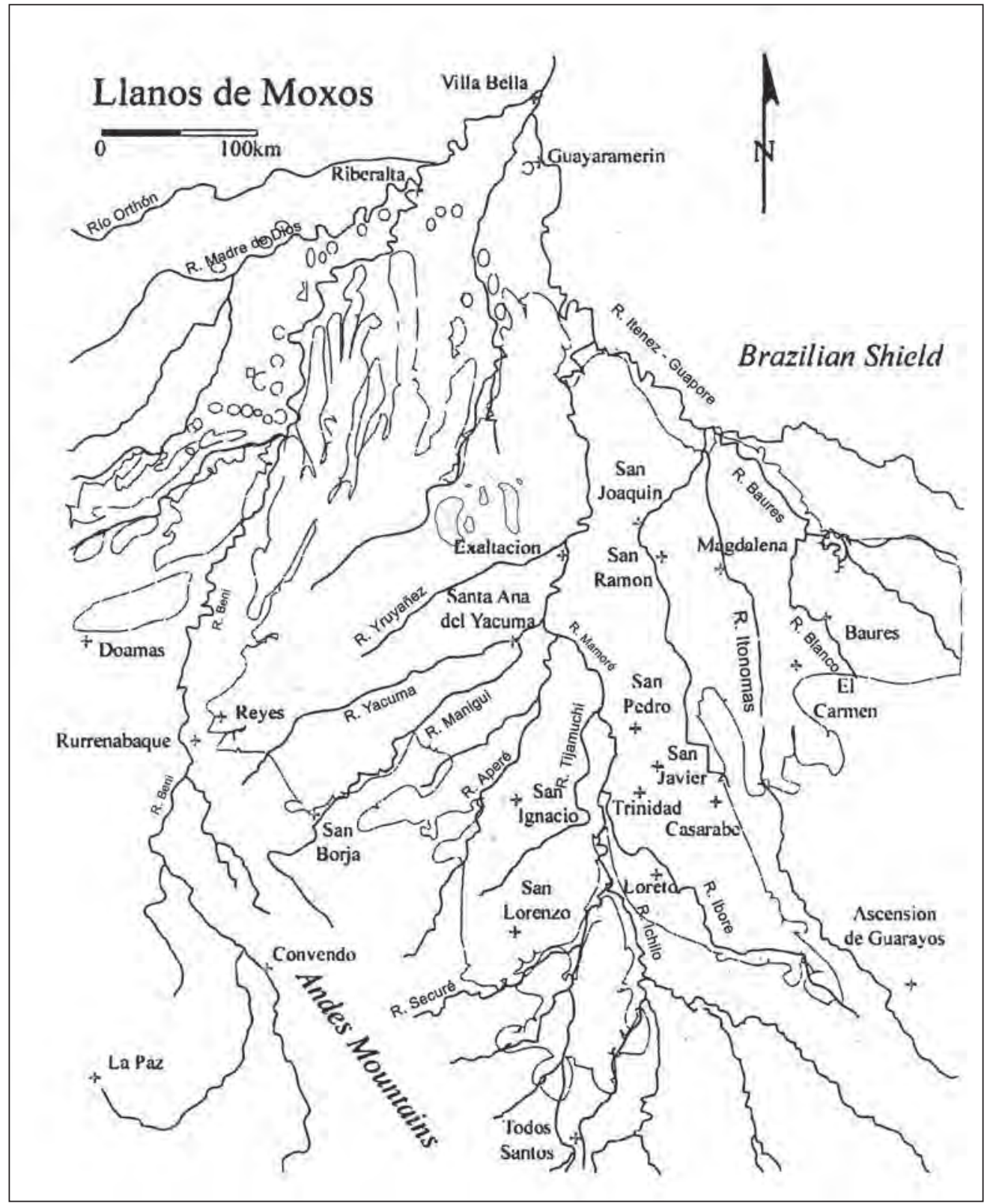

Figura 2. Mapa de los Llanos de Mojos con sus principales sistemas fluviales. Tomado de Walker (1999). 
vegetal altamente fragmentada, caracterizada por la presencia de decenas de ríos (que colectan indistintamente al Beni, Madre de dios, Mamoré y Itenez), lagos (Fig. 3) (el lago Rogoaguado tiene $520 \mathrm{~km}^{2}$ aproximadamente), bosques de ríos o bosques de galerías (Fig. 4), islas de bosque (Fig. 5), arboledas, pajonales, y curiches, bajíos o huiricos (áreas de depresión en las sabanas, siempre inundadas).

El régimen de inundación estacional de los Llanos de Mojos es probablemente una de sus más cruciales características, la cual afecta, como bien menciona Denevan (1966), todos los aspectos del paisaje físico y cultural: el drenaje, los suelos, la vegetación, la vida silvestre, el uso de la tierra y la habilitación. Esta situación depende mucho del régimen pluvial andino (más que la precipitación local) y la inundación temporal, generalmente entre los meses de diciembre a marzo, esta acondicionada por este factor y la capacidad de drenaje del río Itenez-Guapore hacia el norte, que queda rebasada periódicamente.

Este territorio incluye una cantidad de rasgos físicos adicionales que fueron comprendidos sistemáticamente por primera vez en el inventario cultural de Denevan (1966) y que después han ido tipificándose como rasgos del paisaje cultural de los llanos en conjunto (Dougherty y Calandra 1981, 1981-82, 1984; Erikson 1980, 2000, 2006; entre otros), especialmente desde el advenimiento de la fotografía aérea en la zona a partir de los años 50; estos rasgos, según Dougherty y Calandra (1984), incluyen los siguientes elementos: campos elevados (Fig. 6), campos de lomas, campos de zanjas, campos de montículos, campos de rejillas (gridiron fields), zanjas de drenaje y terraplenes (Fig. 7); a los que se pueden agregar, según Erikson (2006), canales, montículos, sitios con zanjas circulares, e islas de bosque (Fig. 8).

La mayoría de las características del paisaje físico de los Llanos de Mojos han sido advertidas desde el inicio de las investigaciones culturales sistemáticas en la zona, que datan todas de los inicios del siglo XX, y muchos de estos rasgos se han adscrito fundamentalmente como particularidades de la ocupación cultural de los llanos para su periodo arqueológico. Hasta entrada la segunda mitad del

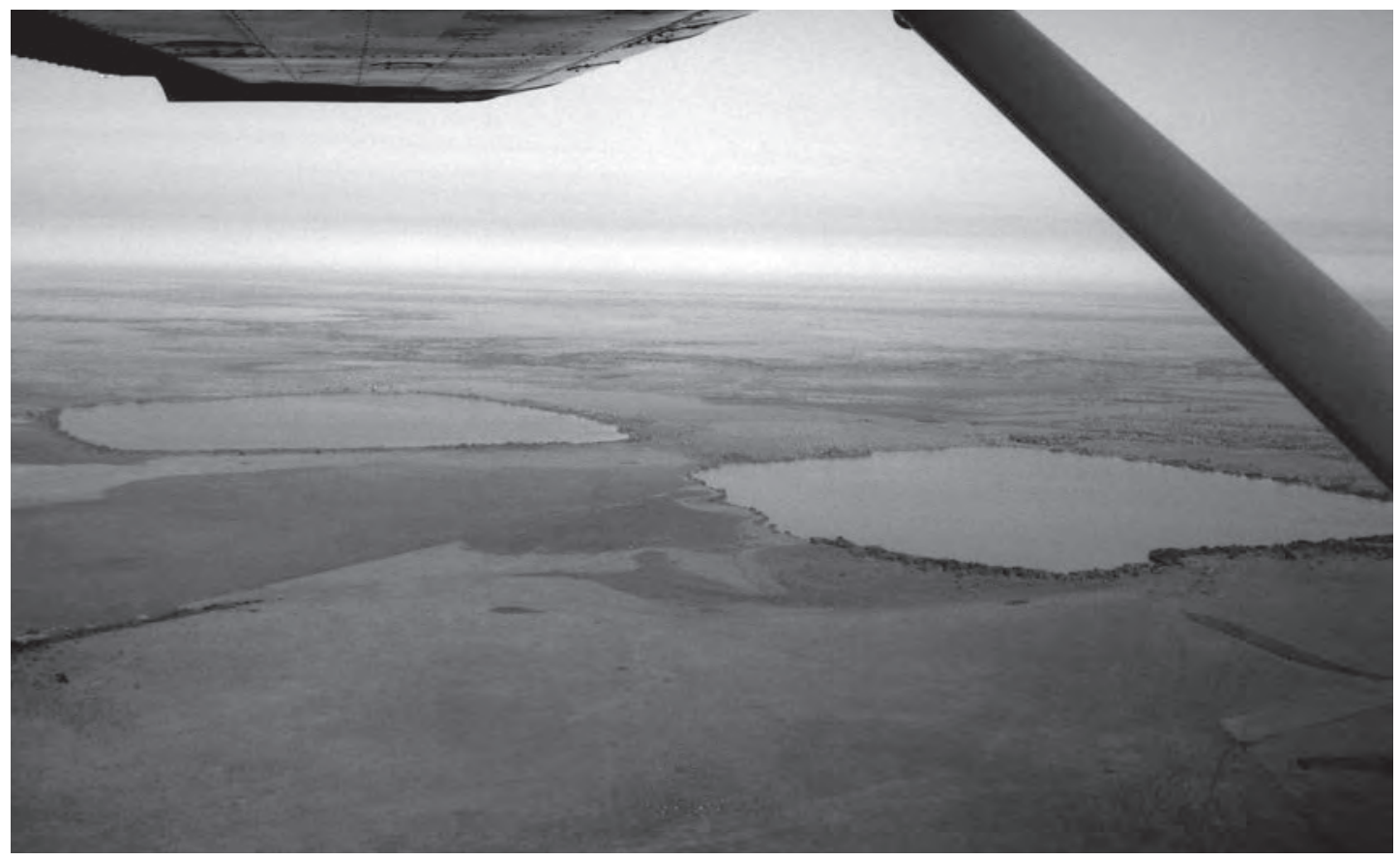

Figura 3. Lagunas artificiales cuadrangulares, Llanos de Mojos. Fotografía de Gori Echevarría, 2006. 


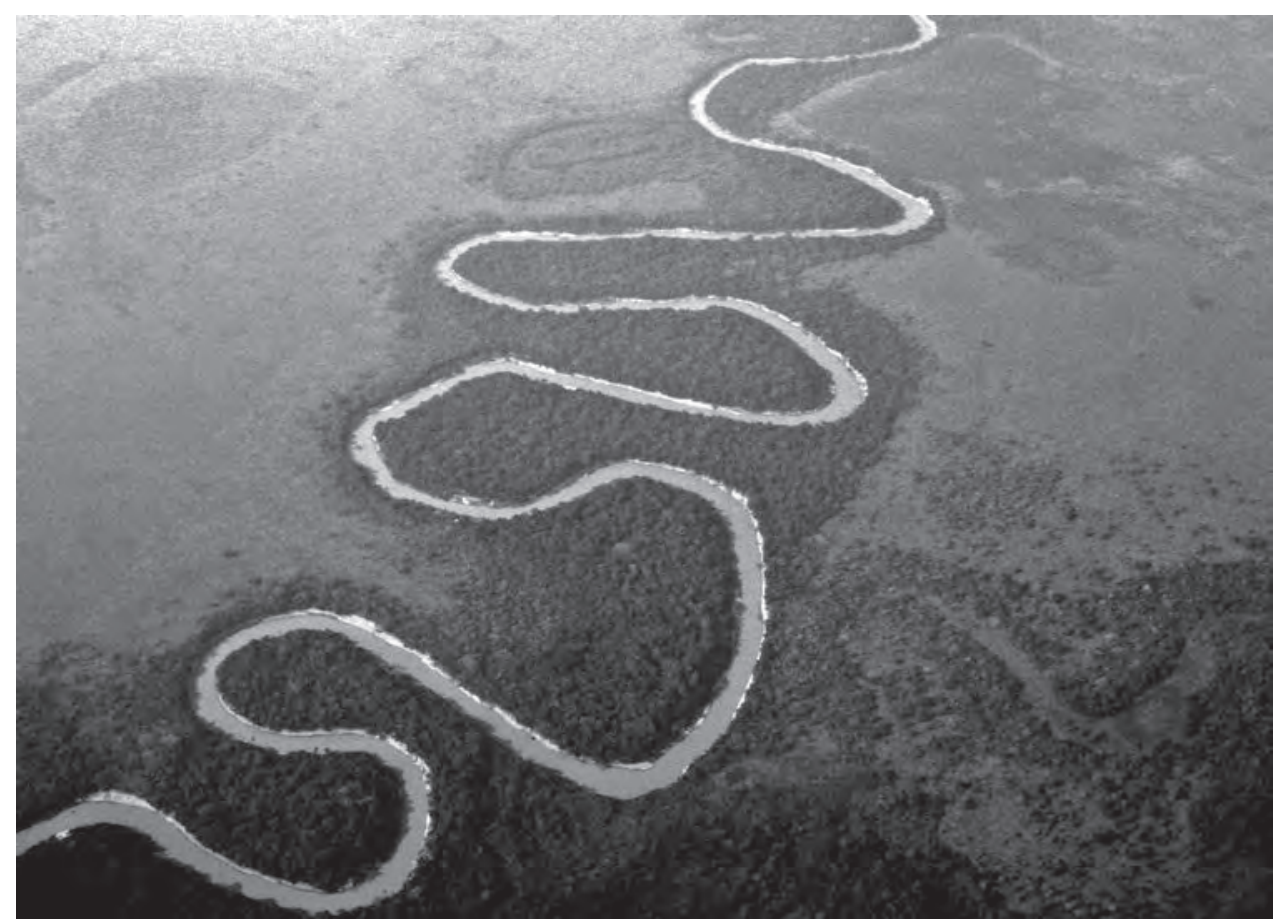

Figura 4. Bosque de galería siguiendo el curso de un río, Llanos de Mojos. Fotografía de Gori Echevarría, 2006.

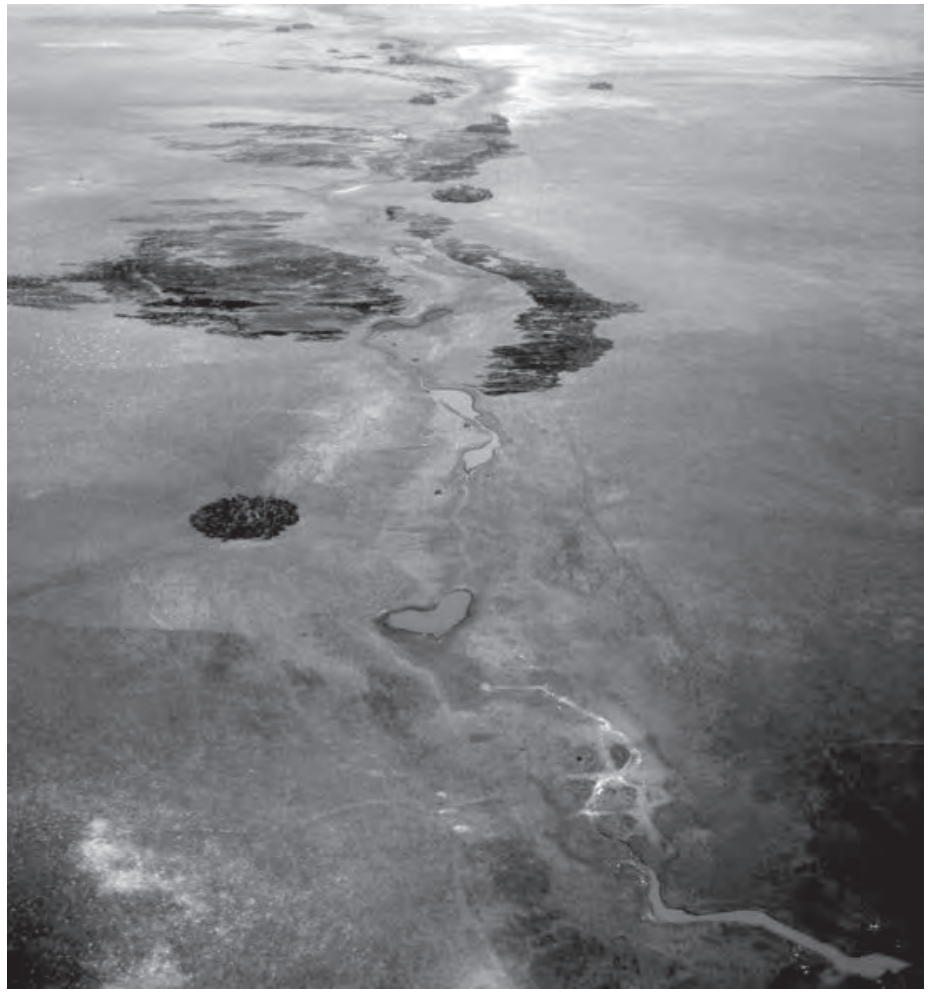

Figura 5. Isla de bosque en medio de un llano inundable, Llanos de Mojos. Fotografía de Gori Echevarría, 2006. 


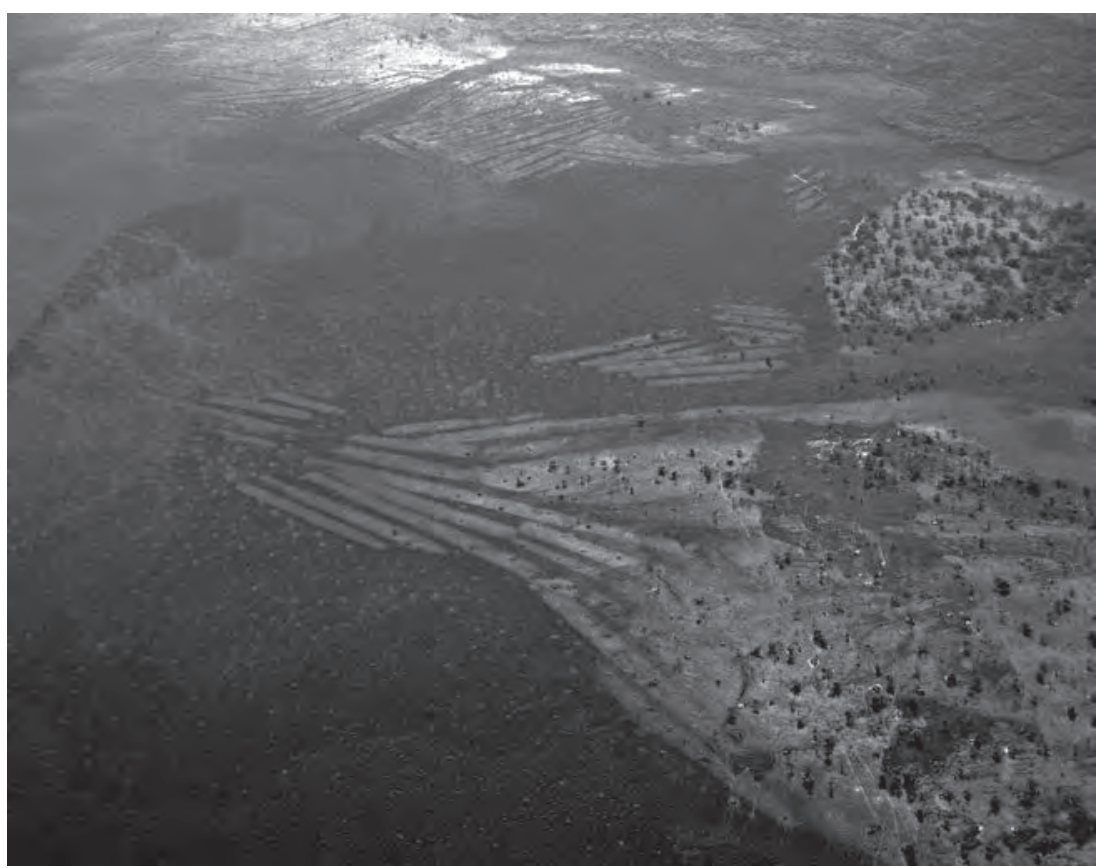

Figura 6. Campos elevados, Llanos de Mojos. Fotografía de Gori Echevarría, 2006.

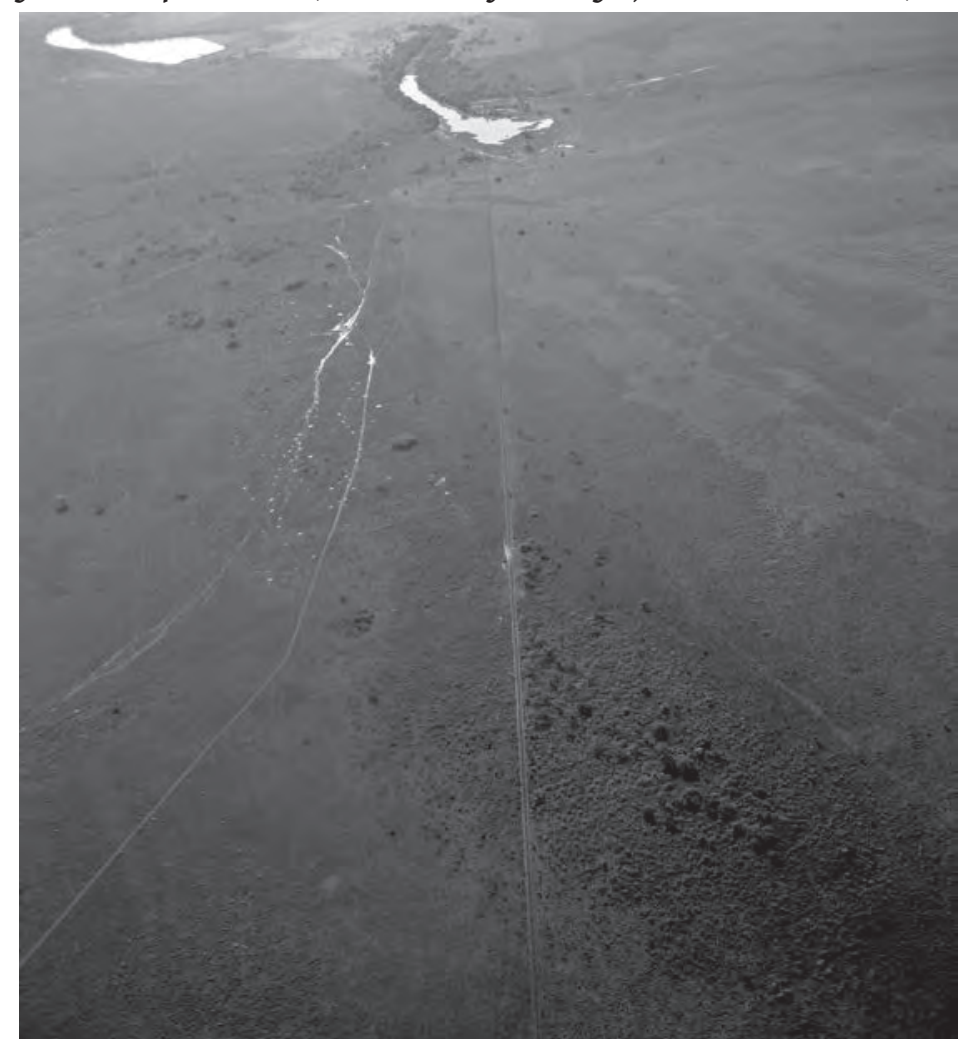

Figura 7. Terraplén lineal atravesando el llano, Llanos de Mojos. Fotografía de Gori Echevarría, 2006. 


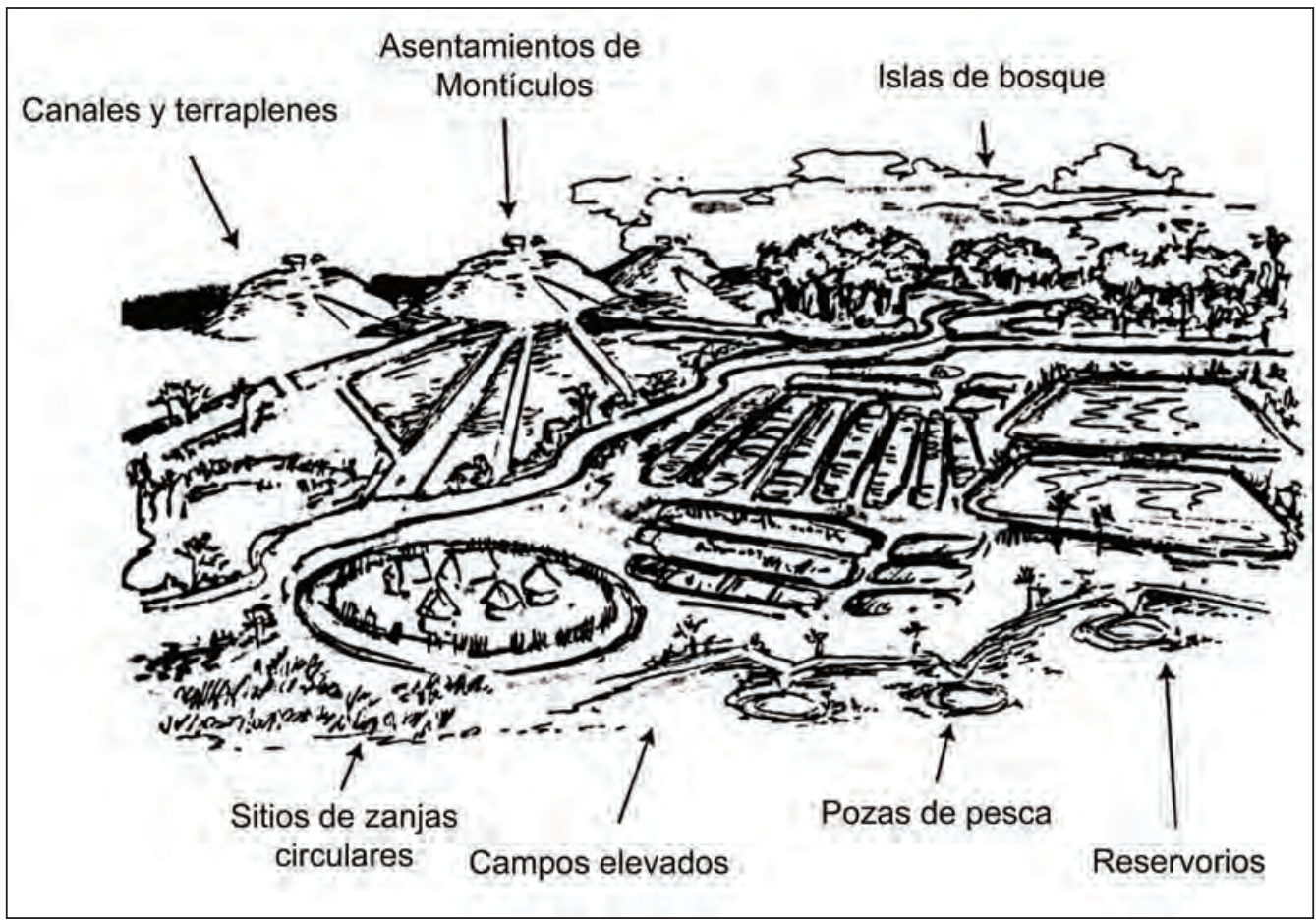

Figura 8. Rasgos culturales y obras de tierra que caracterizan los Llanos de Mojos (Tomado de Erickson 2006).

siglo pasado, estos mismos rasgos no habían servido como índices directos para diagnosticar el tipo de ocupación cultural moderna de la zona, lo que separa ambos periodos, encontrándose que los grupos culturales actuales están caracterizados por una agricultura de roza, habiendo sido tipificados antropológicamente como jefaturas de floresta tropical por Steward y Faron (1959) ${ }^{1}$.

Aunque como dijimos la investigación científica en los Llanos de Mojos empieza recién en el siglo $\mathrm{XX}$, la zona ya había sido objeto de reconocimientos esporádicos desde el siglo XIX, y se puede mencionar por ejemplo a F. J. Eder (1985[1772]), Thadesus Hanke (1796) o Alcides D’Orbigny (1835-1847) como figuras relevantes. No obstante estos autores, a partir de D’Orbigny hasta 1894 en que José Manuel Pando reconoce el territorio, al menos 17 grandes exploraciones tomaron lugar y fueron hechas siguiendo variados intereses, políticos o naturalistas, de diverso valor científico y académico (Cuellar 2003).

Ya en el siglo XX destacan, entre otros, el sueco Erland Nordenskiöld (1910, 1913, 1924) quien, como bien menciona Portugal (1978), excava en los montículos llamados Velarde, Hernmarck, y Masicito cerca de Trinidad; Stig Ryden $(1941,1964)$, que exploró la Loma Alta de Casarabe; Alfred Metraux, que hizo un notable trabajo etnográfico en los llanos en conjunto (1942); Wanda Haenke (1957) por sus estudios en Eviato, cerca de Casarabé; William Denevan (1966) por su clásico estudio sobre geografía cultural de los Llanos de Mojos; Víctor Bustos $(1976,1978)$ por el Instituto Nacional de Arqueología, quien entre 1975 y 1977 excava las lomas Cachipere, Mendoza, Córdova, Suarez, y Ortiz cerca de Trinidad; y Max Portugal que se enfoca en la arqueología del Beni (1978).

1 «[...] diversos grupos de indios [...] cuya cultura consistió de una combinación de elementos derivados de la floresta tropical y de los andes pero cuyos patrones económicos, sociales, políticos y religiosos recuerdan aquellos de las jefaturas del área circum Caribe más que aquellos de sus vecinos inmediatos[...]» (Steward y Faron 1959: 252, traducción mía) 
Más recientemente, trabajos arqueológicos en la zona han sido llevados a cabo por la Misión Argentina entre 1977 y 1981 dirigidos por Bernard Dougherty y Horacio Calandra que se enfocaron en la zona del Mojos Central, el río Itonomas, y últimamente en la cuenca media y baja del Beni; también los de Alicia Fernandez Distel en la loma de Eviato-Casarabe (1987), y se debe mencionar los estudios de Clarck Erikson en la zona del Mojos Central y desde el 2000 en la zona de Ibibate al este de Trinidad. Son importantes los trabajos de Marcos Michel en San Ignacio de Moxos (1993); John Walker en la cuenca de Iruyañez-Omi con excavaciones de Lomas y asentamientos (1999, 2011); los estudios de Jorge Arellano en Trinidad y la cuenca del Orthon (1978, 2002), los de la Misión de la Universidad de Varsovia en el medio Beni desde el 2004 (2008a, 2008b), los trabajos de La Misión Española en la cuenca media del río Aperé cerca de San Ignacio de Mojos (2004), los de la misión Japonesa en Trinidad el 2005 y 2006 centrados en la excavación de la Loma Pancho Román y extendidos hacia el noroeste de los llanos (Sanematsu 2006; Echevarría 2008a, 2008b; Tyuleneva 2007, 2010); y el proyecto de Heiko Prümers (1999-2007) en Trinidad, en las Lomas Mendoza y Salvatierra (Prümers 2012, Jaimes 2004, 2010a, 2012), entre otros.

Como es evidente, la arqueología de los Llanos de Mojos tiene una considerable trayectoria, sin embargo, en términos generales, muestra una imagen muy fragmentada y no ha logrado desarrollar claramente una visión definitoria de la complejidad cultural y arqueológica del área, la cual aparece aún como una incógnita. Consideramos que esto se debe a varias razones:

En primer lugar a la aceptación tacita de un statu quo cultural, como mencionan Dougherty y Calandra (1984), generado principalmente por las investigaciones de Erland Nordenskiöld quien definió los parámetros de la apreciación arqueológica de los Llanos de Mojos desde 1913 y William Denevan (1966) que estableció la naturaleza física cultural del área desde una perspectiva geográfica-ecológica.

Las propuestas de Nordenskiöld o Denevan, vistas como paradigmas ideales, exponen la región como si se tratara de una unidad geomorfológica-cultural, y muchas investigaciones asumen esto como un hecho implícito por lo que la mayoría de sus objetivos no están centrados en la determinación o caracterización individual de entidades sociales diferenciadas desde una perspectiva culturalista llana. Esta aproximación se encuentra respaldada por el hecho que la cultura etnográfica «Mojos» ha constituido el prototipo social de las poblaciones etnográficas de la zona, especialmente a partir de su contacto con los jesuitas en la segunda mitad del siglo XVII. Mojos, tal como menciona Cortes (2005), designa igualmente un ecosistema de llanuras, la clásica provincia colonial de Mojos, un grupo étnico especifico, y al conjunto de pueblos indígenas de la misma región.

En segundo lugar, debido a la falta de parámetros de articulación general entre las investigaciones arqueológicas de la zona, las cuales generalmente desconocen o no pueden relacionar sus datos entre ellos, lo que imposibilita la definición de contextos de correlación técnica de información ${ }^{2}$. Este aspecto no es necesariamente un defecto en la aproximación arqueológica particular, dependiendo más en las propuestas objetivas de la investigación llevada a cabo, en la enorme escala de territorio que comprende los Llanos de Mojos y en factores materiales, naturales o antrópicos, que afectan los procesos de conservación y definición del registro arqueológico del área.

Por otra parte, a nivel alfarero, destaca el hecho de que hasta el momento no se cuente con una secuencia cerámica definitiva para la zona, y las que se han obtenido en forma más completa no se articulan apropiadamente entre sí. Un ejemplo claro son las secuencias de la Loma Alta de Casarabé excavada por Dougherty y Calandra en 1981, y las de la Loma Mendoza y Loma Salvatierra elaborada por la arqueóloga Boliviana Carla Jaimes, bajo el proyecto alemán de Heiko Prümers (Jaimes 2004,

2 Esto se puede observar al considerar las aproximaciones y discusiones sobre a la naturaleza cultural de los campos elevados, montículos, terraplenes, y en general de la obras de tierra de la región, obras que han servido como variables básicas para la definición de sitios arqueológicos en el área. Un ejemplo de este tipo de discusión se puede ver en Earthmovers of the Amazon de Charles C. Mann (2000). 
2010a). En ambos casos las variables diagnosticas utilizadas no son completamente contrastables, y a nivel estilístico las correlaciones son claramente ambiguas por lo que algunos tipos estilísticos de fases singulares en Loma Alta pueden relacionarse, por ejemplo, con tipos de tres diferentes fases en la Loma Mendoza. Aunque la secuencia general de los sitios parece traslaparse, no se tienen suficientes parámetros de correlación para una información material definida y el establecimiento de comparaciones horizontales más estables ${ }^{3}$. Loma Alta de Casarabé y Loma Mendoza están separadas por menos de un kilómetro.

Hasta ahora una sensación de indefinición cultural se puede percibir en la arqueología de Mojos central y la evidencia cerámica, que es una de las más comunes de abordar en la zona, no está ayudando a aclarar el panorama social debido su complejidad formal decorativa. Hay que destacar además que la presencia de diferentes y excluyentes estilos cerámicos en lomas o montículos cercanos, ha obstaculizado una explicación general coherente para el establecimiento de relaciones culturales, habiéndose planteado la existencia de localismos estilísticos (Dougherty y Calandra 1981-1982), o variaciones funcionales con cargas decorativas diferenciadas (Jaimes 2010b), aunque todavía queda mucho que investigar al respecto.

La arqueología de los Llanos de Mojos vista como un bloque conjunto cubre un plano temporal único dentro de la cronología histórica de este territorio ${ }^{4}$, y como hemos visto su definición va a depender todavía de más estudios sistemáticos. En este sentido hay que decir que es cierto que aún no existe una propuesta consensuada de ninguna entidad sociocultural arqueológica en los llanos, sincrónica y diacrónica, sobre la base de sus propios materiales, y la mayoría de los planteamientos sobre articulación arqueológica se basan fundamentalmente en apreciaciones e hipótesis sobre el tipo de aprovechamiento económico, genéricos patrones de asentamiento, tipos de construcción o la exposición de evidencia aislada; lo que indica que la investigación es todavía fragmentada y su articulación aún difícil.

Las culturas arqueológicas más probables, consideradas sobre la base de diferentes patrones, monumentales, económicos, estilos cerámicos, etc, son: la cultura de los grandes montículos, extendida entre las cuencas de los ríos Mamoré, Ibaré, Caimanes, Tijamuchi, Apere, Matos, Isiboro, Blanco, y Securé, y sus tributarios (Fig. 9) (exceptuando el río Blanco, esta distribución coincide con la cuenca alta del Mamoré); la cultura de Iténez-Baures caracterizada por asentamientos con zanjas anchas profundas circulares o elípticas (Fig. 10) (Dougherty y Calandra 1984-1985, Calandra y Salceda 2004, Erickson 2006, 2010), y la cultura de «los grandes lagos» en la zona norcentral, cuyos asentamientos consisten de probables aldeas de marisqueros y pescadores con campos elevados y cerámica pintada (Figs. 11 y 12). Las zonas más hacia el oeste y noroeste (ríos Beni, Madre de Dios, Orthon), que no presentan los caracteres mencionados, parecen estar más condicionadas por la selva tropical (Calandra y Salceda 2004) sin una cultura diversificada o monumental, aunque todavía deben hacerse más estudios.

3 Respecto a las secuencias de Loma Alta de Casarabe y Loma Salvatierra, la propia Jaimes relativiza sus correlaciones cerámicas cuando dice: «La Fase Casarabe corresponde a la fase 1 de la Loma Salvatierra, algunos tipos cerámicos de la fase Mamoré, podrían encontrarse en la fase 2 y la fase San Juan de la loma Alta de Carabe, parece corresponder con la fase 3 de la Loma Salvatierra» (Jaimes 2010b: 87). En su tesis del 2010 Jaimes dice: «La fase Casarabe de la Loma Alta de Casarabe podría ser equivalente a la fase 1 de la Loma Salvatierra» (Jaimes 2010a: 170). El subrayado es mio.

4 John Walker (1999), propuso una secuencia de cuatro periodos para los cambios en densidad poblacional, intensidad agrícola, y organización social de la zona de los ríos Iruyañez - Omi, que me parece bastante apropiado para ilustrar la cronología general del área:

1er Periodo Prehispánico. Empieza en un punto indeterminado y termina en 1492 (llegada de Colón a América)

2do Periodo Protohistórico. Empieza en 1492 y termina al arribo de las misiones jesuitas en 1693.

3er Periodo de las Misiones. Empieza en 1693 y termina con la expulsión de los Jesuitas en 1767.

4to Periodo Moderno: Desde 1767 hasta hoy. 


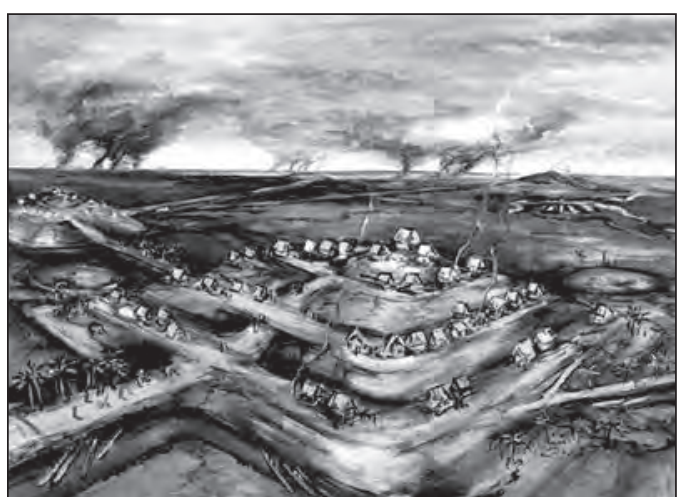

Figura 9. Representación de la cultura de los grandes montículos, Llanos de Mojos (Tomado de Mann 2000).

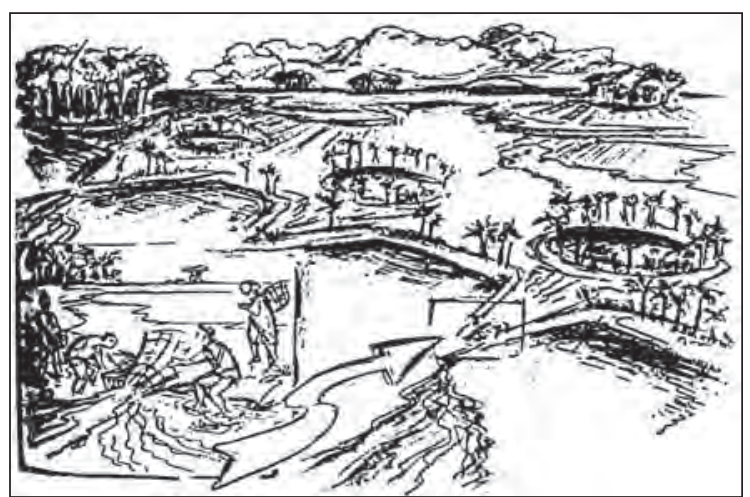

Figura 10. Representación de la cultura Iténez - Baures, Llanos de Mojos (Tomado de Erickson 2006).

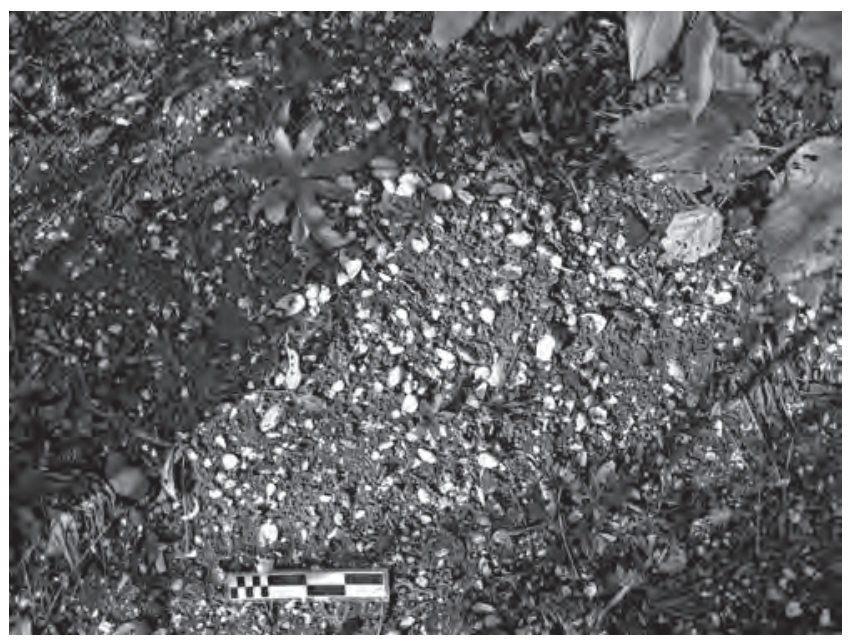

Figura 11. Montículos de concha y tierra, cultura de los lagos. Fotografía de Gori Echevarría, 2006

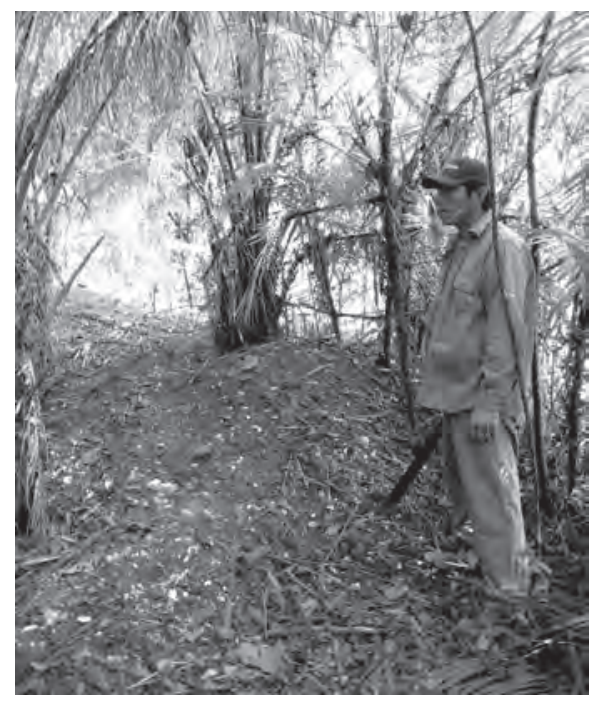

Figura 12. Vista superficial de los conchales expuestos, cultura de los lagos. Fotografía de Gori Echevarría, 2006

Es importante ponderar que las culturas propuestas aquí, que pueden separarse espacialmente en el territorio actual de los Llanos de Mojos (Fig. 13), implican la consideración de un momento singular en la historia arqueológica de la región, el último de la secuencia cultural arqueológica, cuyo pasado, como se puede inferir, es grandemente desconocido en la mayoría de sus elementos.

La correlación entre los materiales arqueológicos y la información histórica o etnografía reconocida es también un punto de controversia y no ayuda a establecer una continuación en la secuencia histórica de los Llanos de Mojos. Dougherty y Calandra concluyen en una sentencia, un hecho que puede ser diagnóstico para todos los Llanos de Mojos en conjunto: «La primera conclusión a la que arribamos al momento presente, es que, para el área donde vivieron los Mojo, el universo artefactual prehispánico no coincide del todo con lo poco que ha sido informado acerca de su cerámica y otros escasos imperecederos objetos» (1984: 182. Traducción mía). Es importante destacar que Dougherty y Calandra han explorado y excavado más de 50 sitios arqueológicos entre la zona del Mojos Central, al este de Mojos (Iténez) y en la cuenca del Beni entre Rurrenabaque y Riberalta. 


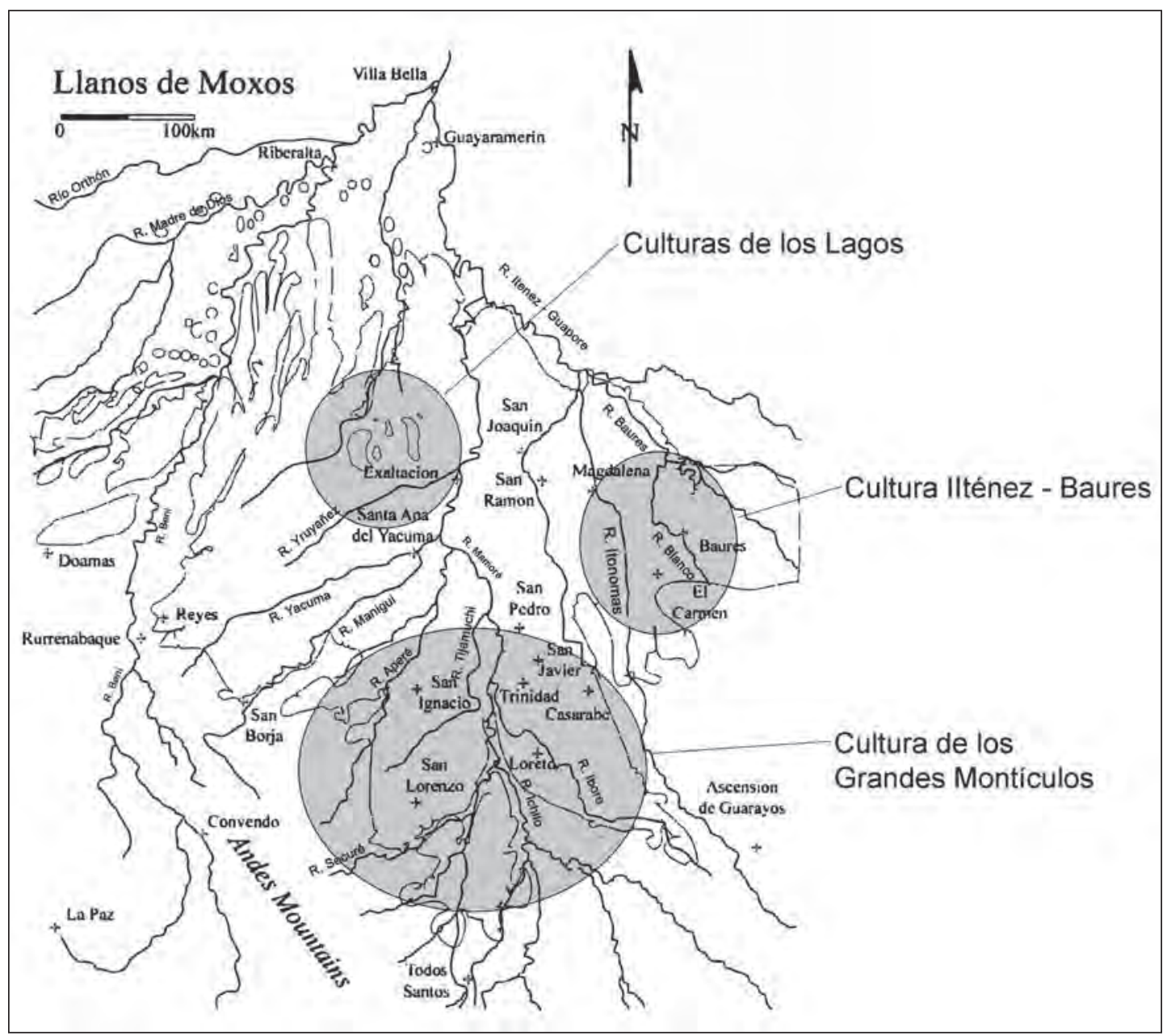

Figura 13. Mapa de los Llanos de Mojos con las subdivisiones culturales para los Llanos de Lojos propuestas en el texto.

Jhon Walker ha determinado, mediante su estudio de los campos agrícolas de Iruyañez-Omi que los sitios de campos elevados fueron abandonados al menos 100 años antes de la llegada de los españoles a América. De sus hipótesis sobre este hecho, las que se relacionan al cambio climático (hipótesis medioambientalista), al contacto poblacional (hipótesis poblacionista) y al cambio cultural; la última ha probado ser la más acertada. Según Walker «el cambio en la organización social de los agricultores de campos elevados fue el factor singular más importante para el abandono de la agricultura de campos elevados» (1999: 180. Traducción mía).

En la actualidad hay un consenso en que la mayoría, sino todos, los campos elevados de los Llanos de Mojos, ya habían sido abandonados cuando los primeros misioneros jesuitas arribaron a la zona, y no existen cronologías transicionales en los sitios arqueológicos reconocidos que vinculen los sitios a la colonia o a las misiones, incluso cuando se han reportado materiales del Tahuantinsuyu hacia la cuenca del Beni (Portugal 1978). Los grupos culturales de los Llanos de Mojos (Fig. 14), identificados mediante documentación histórica, entre los de lengua Arawak: Moxo y Bauré, y los de lenguajes no clasificados: Cayuvava, Canichaca, Itonama y Movima, quedan de esta forma flotando en un limbo 


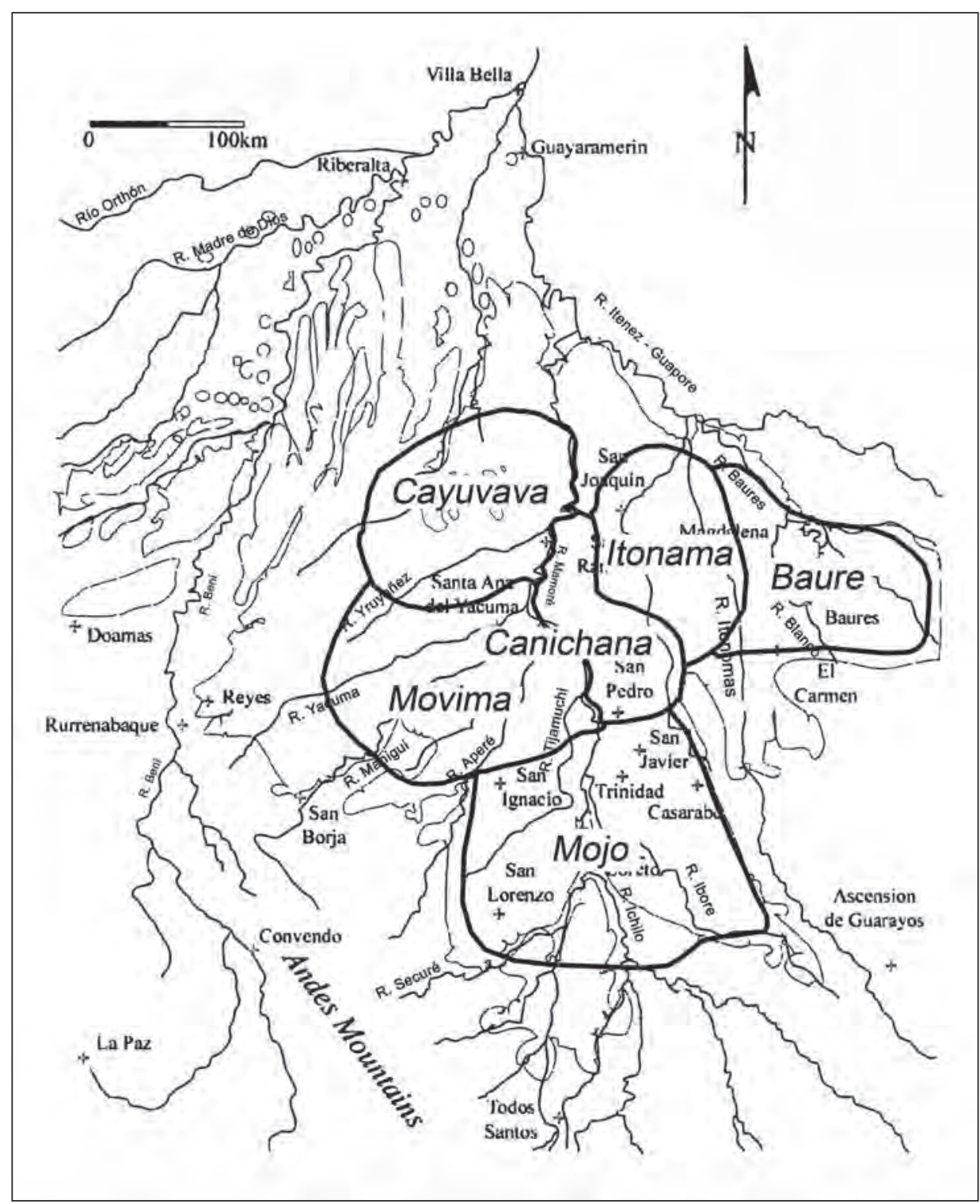

Figura 14. Mapa de los grupos culturales etnográficos reconocidos en los Llanos de Mojos (Tomado de Walker 1999).

cultural, y su vinculación con el pasado de los llanos, caracterizado genéricamente por los trabajos en tierra, queda separado por un hiatus estratigráfico contundente. ¿Qué paso en los Llanos de Mojos antes de la llegada de los españoles? Es una pregunta aún por responder.

\section{ExcAVACIONES EN LA CUENCA DEL LAgo Rogaguado}

Nuestra intervención arqueológica se centró en la parte norcentral de los Llanos de Mojos (Fig. 15), en la ribera oeste y noroeste del lago Rogoaguado (Fig. 16), el cual forma parte de un sistema de grandes lagos entre los ríos Mamoré y Beni, al noroeste del poblado Exaltación en la provincia de Yacuma. 


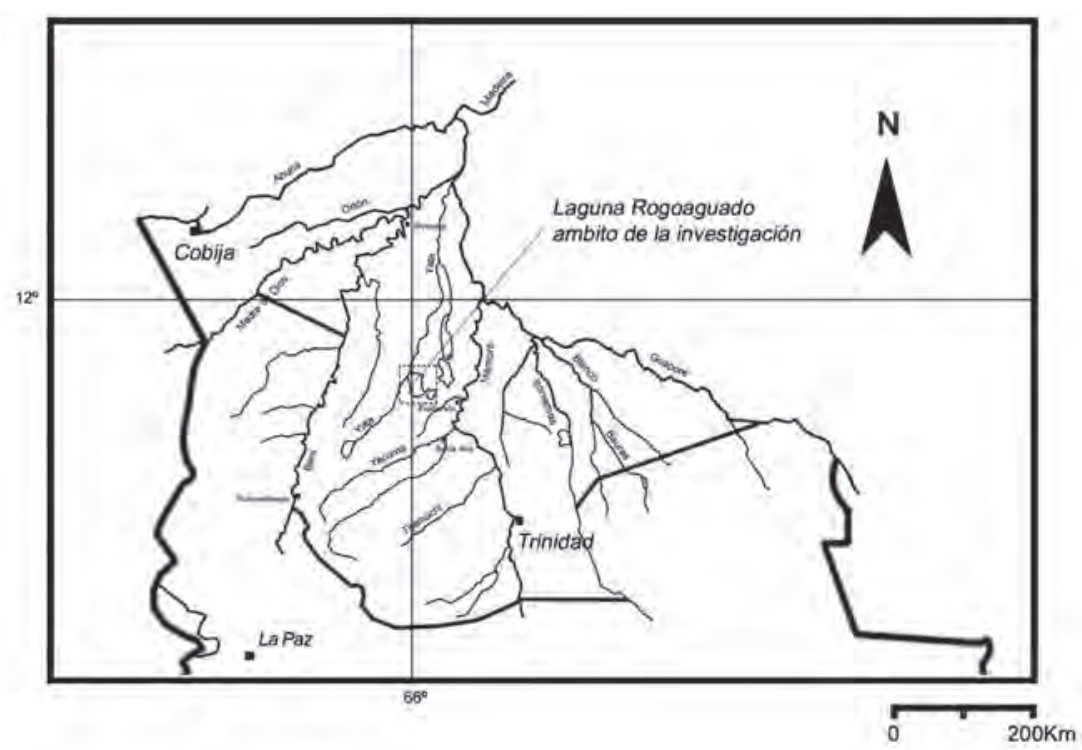

Figura 15. Mapa de los Llanos de Mojos y el área cubierta por el proyecto (recuadro).

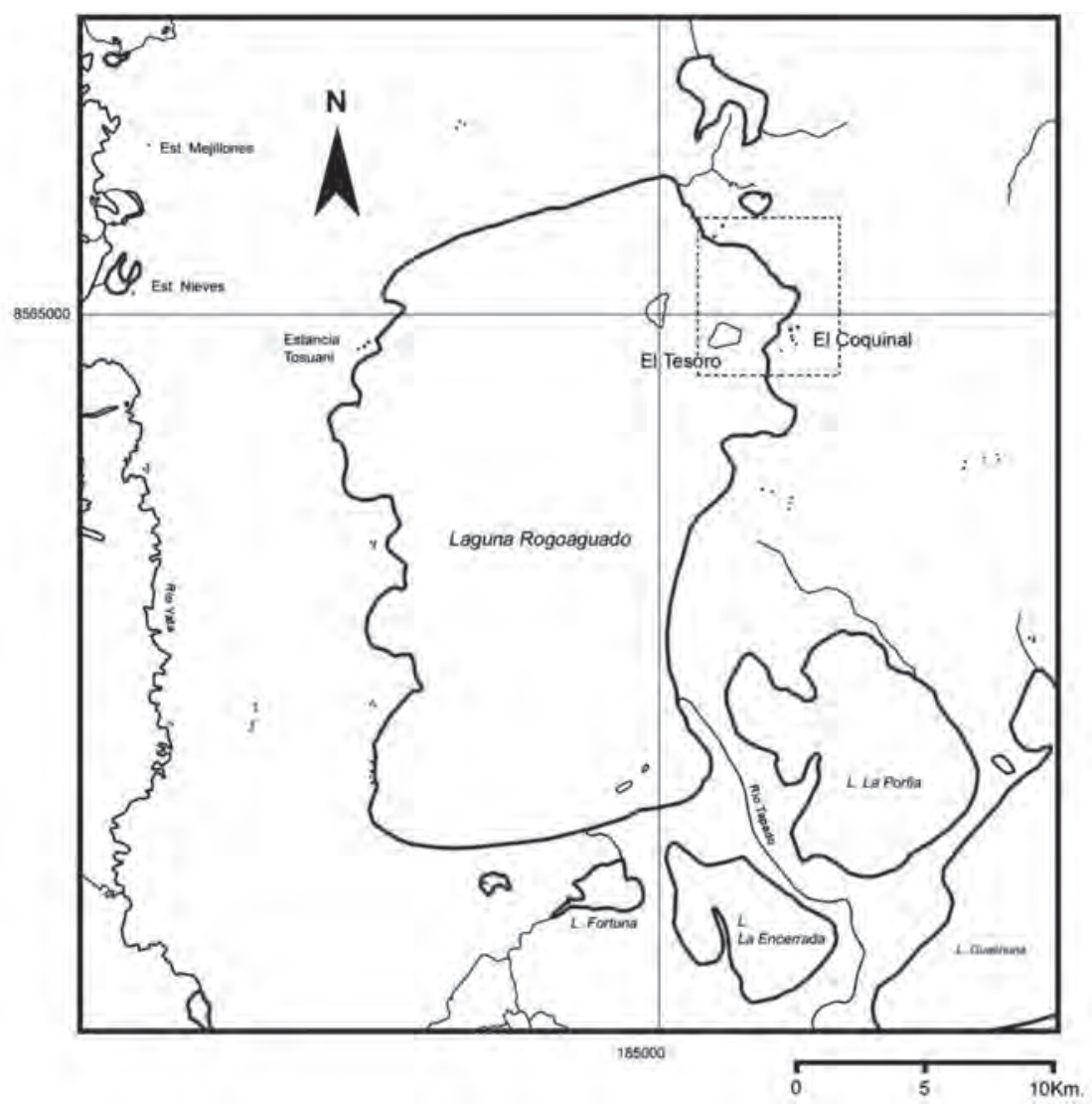

Figura 16. Mapa del lago Rogoaguado con la ubicación de la zona donde se realizaron las investigaciones. Llanos de Mojos. 
Esta intervención se llevó a cabo como un programa externo del Proyecto Llanos de Mojos de la Universidad de Rikkyo, Japón, coordinada por la Antropóloga Vera Tyuleneva de la Universidad de San Petersburgo y ejecutada por el autor de este artículo. La zona en general fue seleccionada por la antropóloga mencionada el año 2005, después de una visita de observación a la región.

La investigación se basó en una premisa histórica: la prospección y el reconocimiento arqueológico parcial del lugar donde se había supuesto la existencia histórica del término «Paititi», que, tal como menciona Tyuleneva (2007), es el «nombre de un territorio, un río, un cerro, una laguna y/o del jefe de cierto grupo étnico (o varios grupos), gobernante del respectivo territorio». Las investigaciones arqueológicas fueron sólo exploratorias, y se desarrollaron paralelamente a las observaciones de la antropóloga Tyuleneva en otros yacimientos arqueológicos alrededor de la laguna Rogoaguado y la cuenca del río Tapado (Fig. 17) (Tyuleneva 2007, 2010; Echevarría 2008a, 2008b).

A partir de los datos iniciales de Tyuleneva, realizamos una exploración detallada de los yacimientos documentando cuatro zonas y cinco sitios arqueológicos (Fig. 18), seleccionado cuatro de los sitios para nuestras excavaciones. Los sitios escogidos fueron los siguientes:

El Tesoro - Sector A (Clave: RO-003)

El Tesoro - Sector B (Clave: RO-003)

Coquinal 2 (Clave: RO-002)

El Paquió 1 - Sector A (Clave: RO-004)

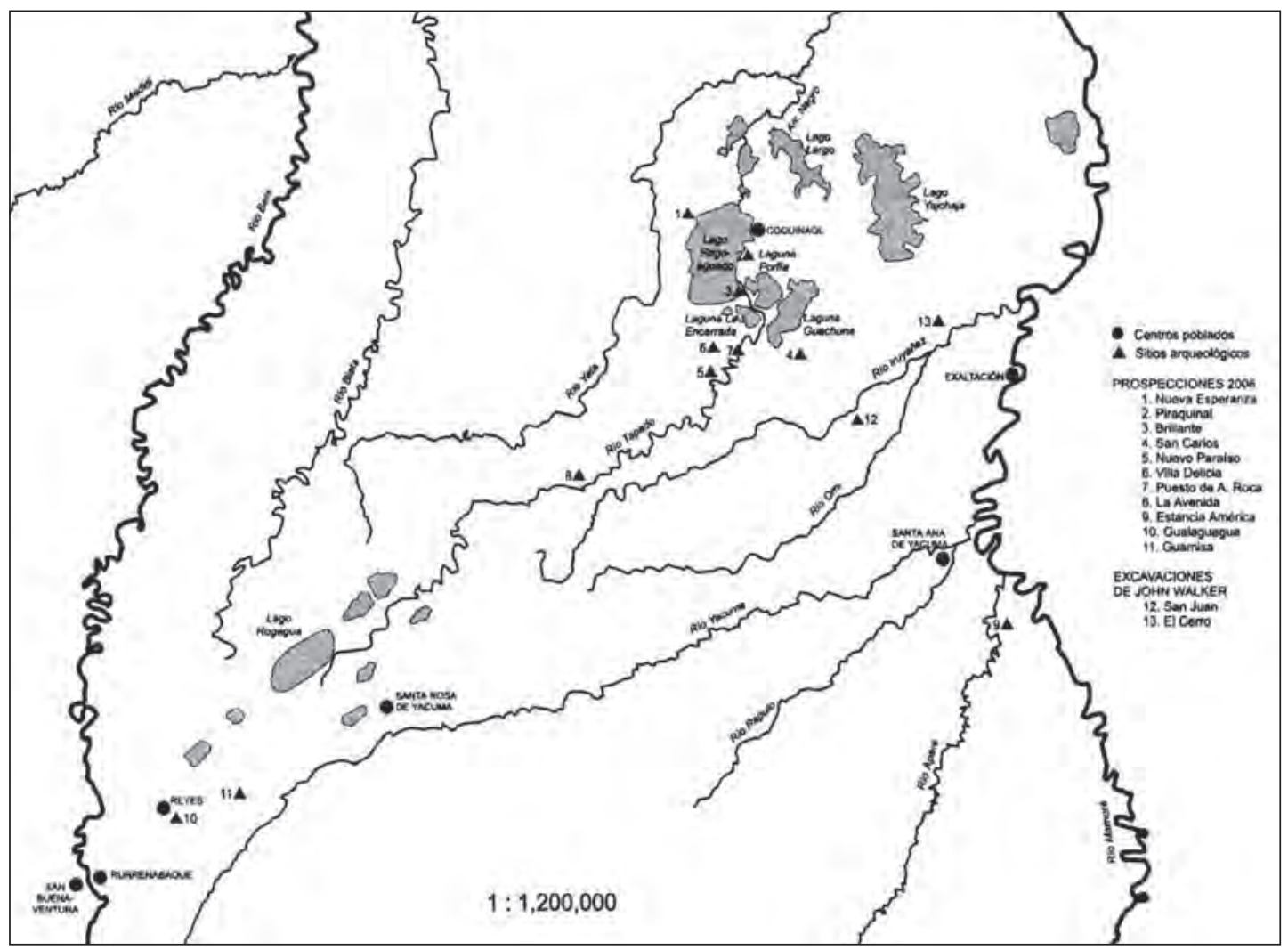

Figura 17. Mapa de la zona explorada por la antropóloga Vera Tyuleneva (Tomado de Tyuleneva 2007). 


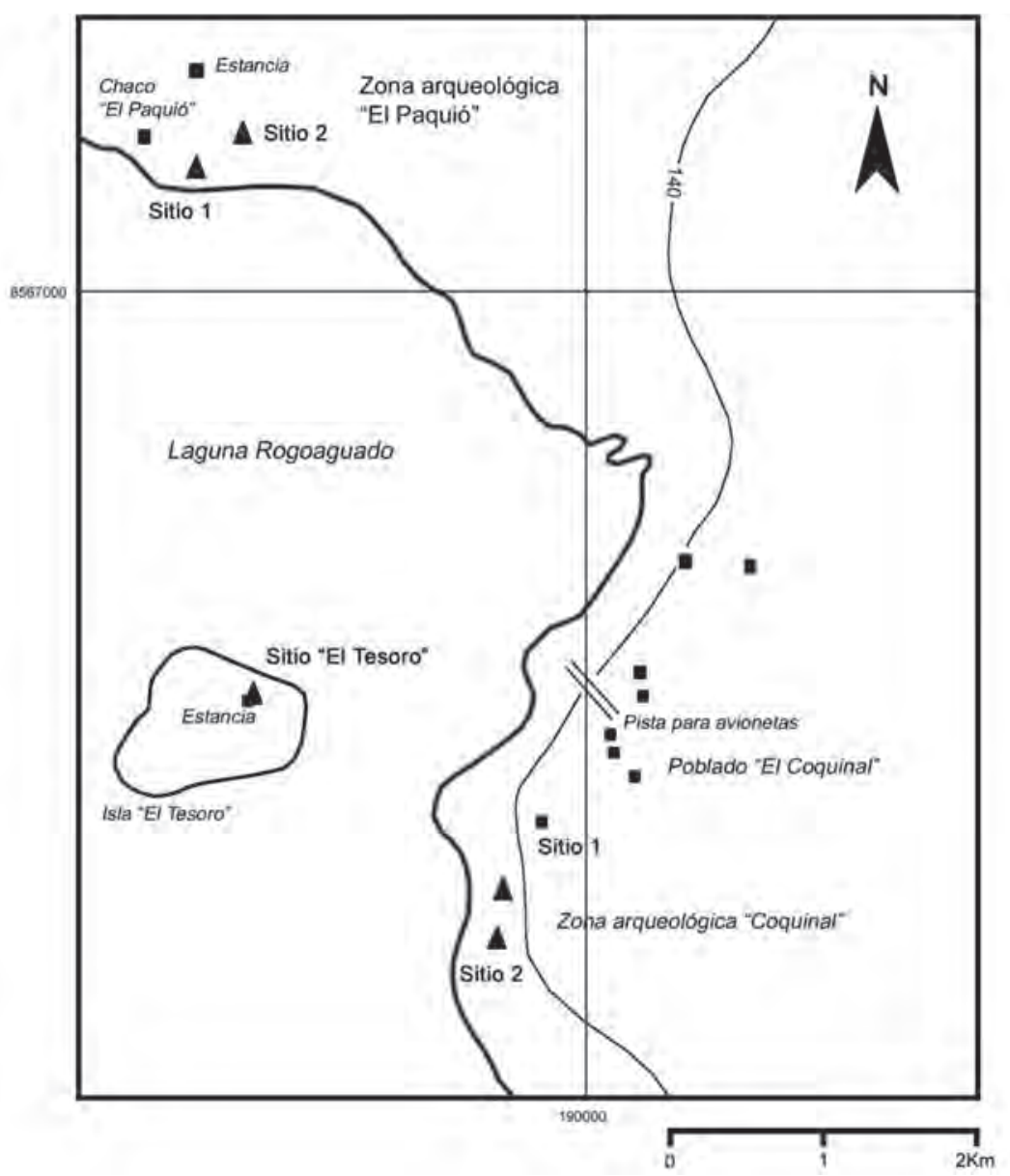

Figura 18. Mapa de la ribera noroeste del lago Rogoaguado con los sitios arqueológicos excavados y mencionados en el texto.

De todos los sitios excavados, el Paquió arrojó una notable cantidad de información arqueológica que tiene que ver con aspectos diversos de las poblaciones pasadas del Rogoaguado, especialmente su economía y forma de vida. Los demás pozos también ofrecieron gran información pero constituyeron yacimientos menos complejos, sin rasgos y contextos arqueológicos independientes, lo que diferenció claramente el Paquió de las demás excavaciones llevadas a cabo en la zona por lo que vamos a extendernos en este yacimiento.

\section{El Paquió}

El sitio arqueológico el Paquió esta conformado por un depósito de conchas, cerámica y otros materiales culturales que en superficie se perciben como montículos bajos y concentraciones extendidas de conchas. La excavación en este sitio cubrió sólo una cuadricula restringida de 2 x 2 m y se seleccionó el área debido a la buena predisposición material del yacimiento, la poca disturbación superficial y el considerable contenido arqueológico expuesto de conchas y cerámica (Figs. 19 y 20). La excavación se hizo por niveles arbitrarios de $10 \mathrm{~cm}$ alcanzándose 14 niveles. Bajo la superficie, todo el yacimiento mostró una completa integridad de contenido sin disturbaciones contemporáneas ni intrusiones. 


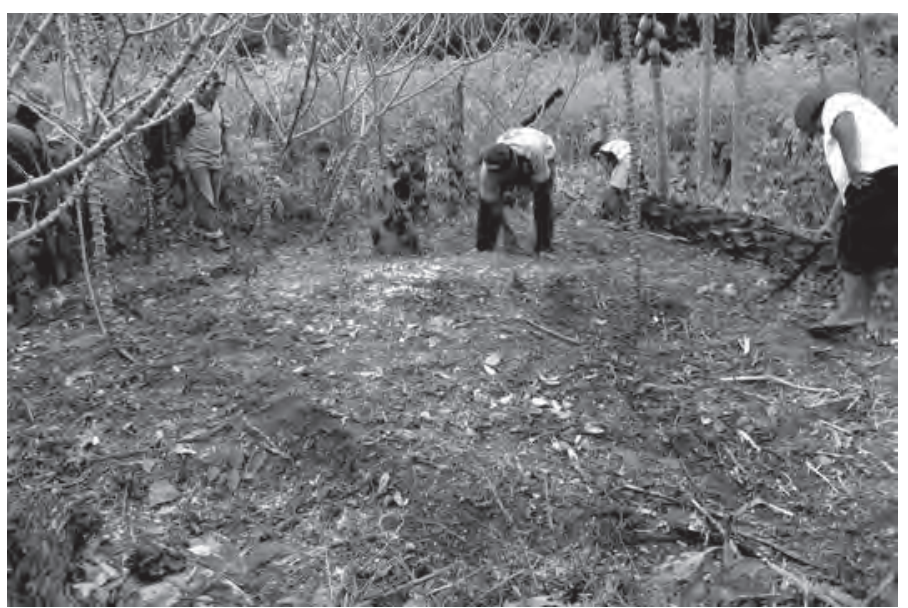

Figura 19. Vista del área seleccionada a excavar, El Paquió 1 - Sector A.

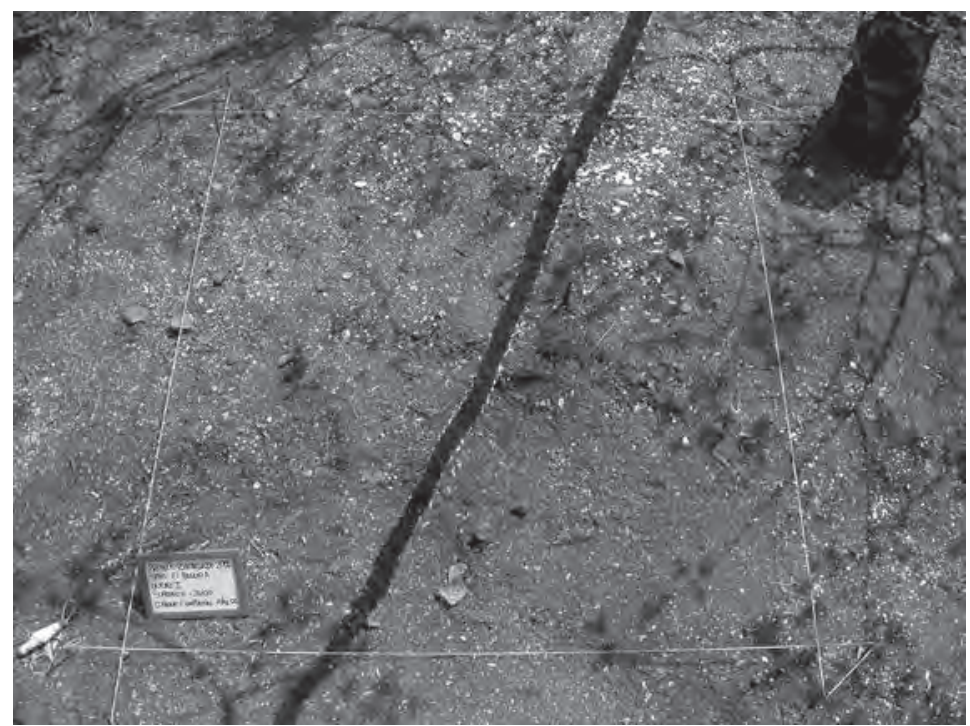

Figura 20. El Paquió. Unidad de Excavación 1, superficie. Fotografía de Gori Echevarría, 2006.

La excavación practicada resultó en la exposición de dos procesos mayores de deposición material cultural. El primero de ellos, más antiguo, caracterizado principalmente por la presencia de un pozo de desechos o conchas formando un contexto original sellado, dos posibles pozos de poste y un probable patrón general de limpieza de los niveles de ocupación relacionados (Niveles 10-14), lo que sugiere una actividad doméstica dirigida (Figs. 21 y 22).

El segundo proceso, más tardío, constituyó la evidencia de un gran depósito de conchas y cerámica en un contexto abierto, que incluía pequeños fogones y acumulaciones de desechos asociados (Figs. 23 y 24). Este contexto se presentó en superficie como un conchal o pequeño montículo con cima apuntada. La acumulación de conchas empezó aproximadamente a un metro de profundidad y se definió concretamente como un depósito fijo en el nivel $6(60 \mathrm{~cm})$, deposición que soportó al menos cinco actividades intrusivas (rasgos) entre las que se encontraron un depósito de cerámica rota (Fig. 25), un pozo de desechos estratificado en tres niveles con cerámica, ceniza, conchas, y fragmentos de bloques de arcilla; un pozo de quema, y un fogón o cocina (Figs. 26 y 27). 


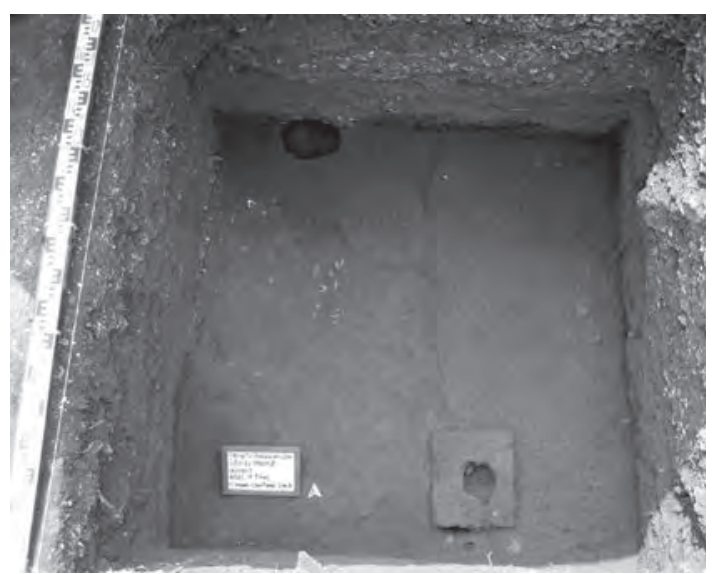

Figura 21. El Paquió. Unidad de Excavación 1, Nivel 14. Fotografía de Gori Echevarría, 2006.

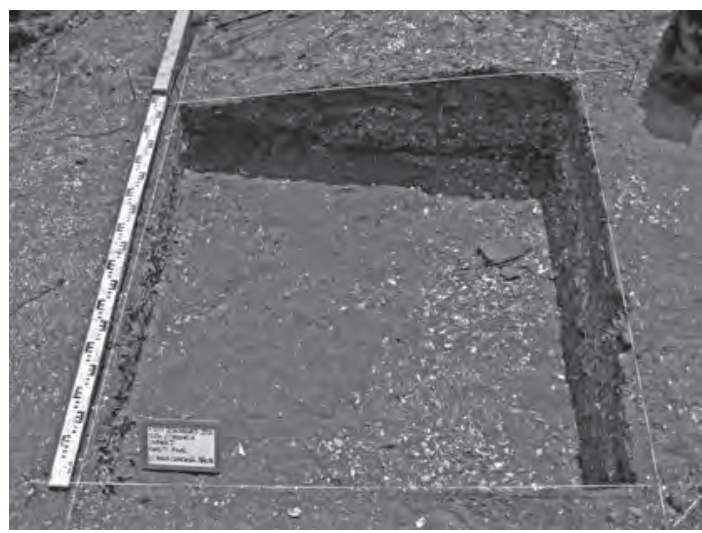

Figura 23. El Paquió. Unidad de Excavación 1, Nivel 7. Fotografía de Gori Echevarría, 2006.

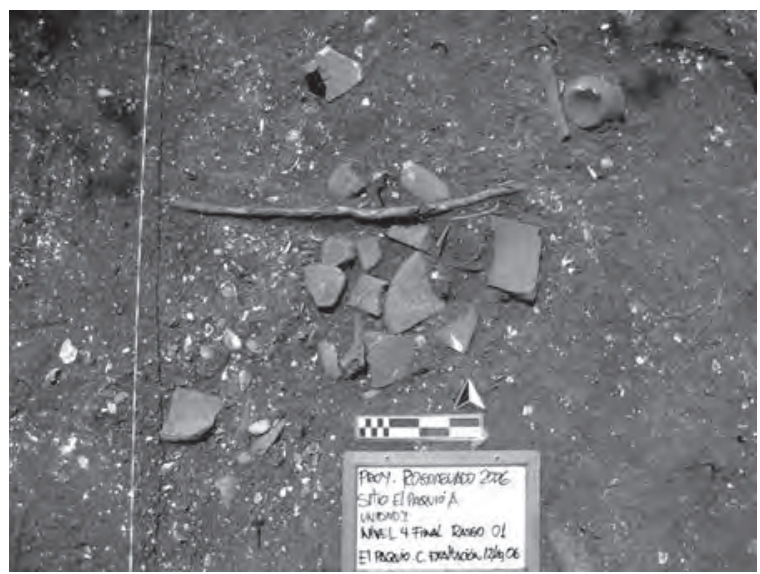

Figura 25. El Paquió. Unidad de Excavación 1, Nivel 4, Rasgo 1. Fotografía de Gori Echevarría, 2006.

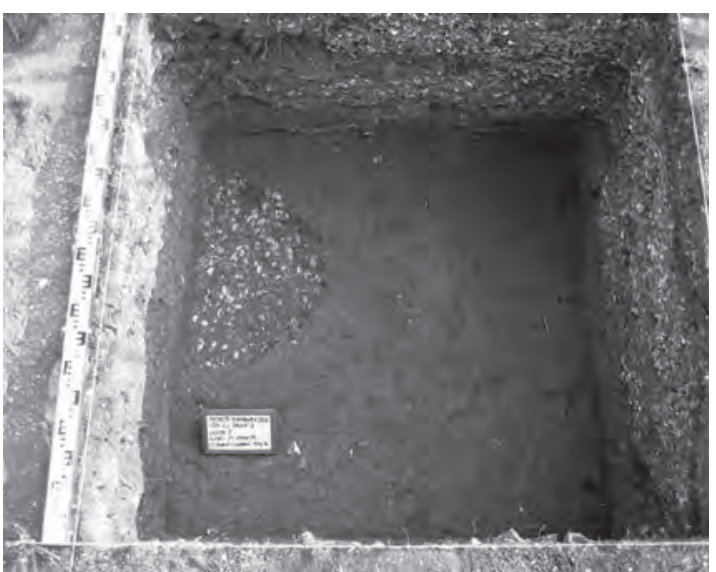

Figura 22. El Paquió. Unidad de Excavación 1, Nivel 14, Rasgo 5. Fotografía de Gori Echevarría, 2006.

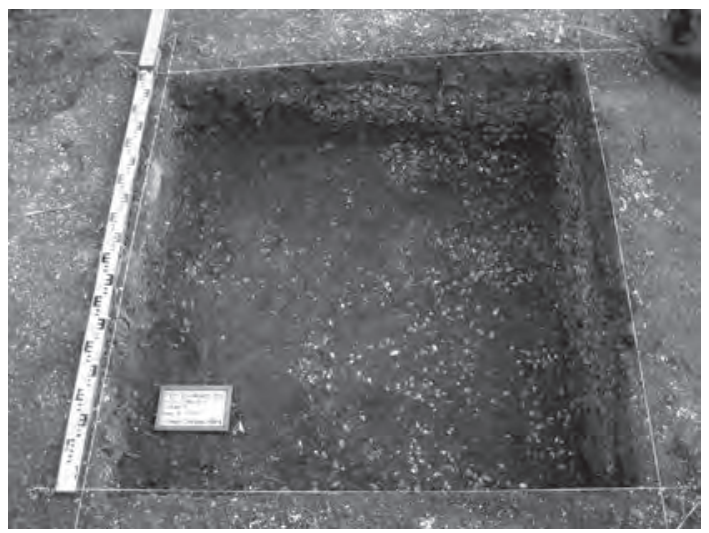

Figura 24. El Paquió. Unidad de Excavación 1, Nivel 8. Fotografía de Gori Echevarría, 2006.

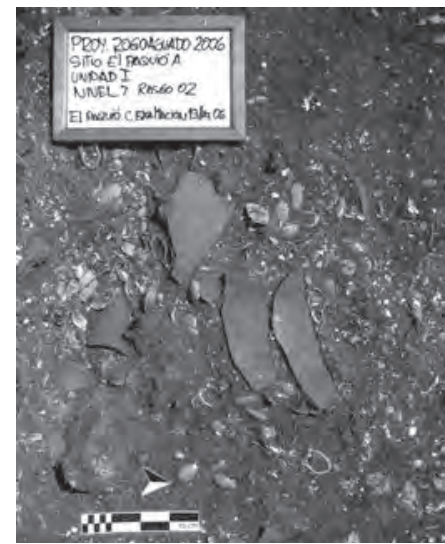

Figura 26. El Paquió. Unidad de Excavación 1, Nivel 7, Rasgo 2, acumulación de cerámica y restos de bloques de arcilla. Fotografía de Gori Echevarría, 2006. 
La evidencia apunta a indicar que este yacimiento se trató de un asentamiento orientado a la explotación de conchas bivalvas lacustres, la cual fue identificada como Leila blainvilliana (Fig. 28). Un producto lacustre que no había sido reportado como objeto de tráfico, o alimento en la documentación del siglo XVII (a menos que se acepte la relación de Juan Recio de León de 1623-1627, que habla de conchas productoras de perlas), y menos en tiempos posteriores. La evidencia del Paquió es incontrovertible para el consumo y el procesamiento de estas conchas.

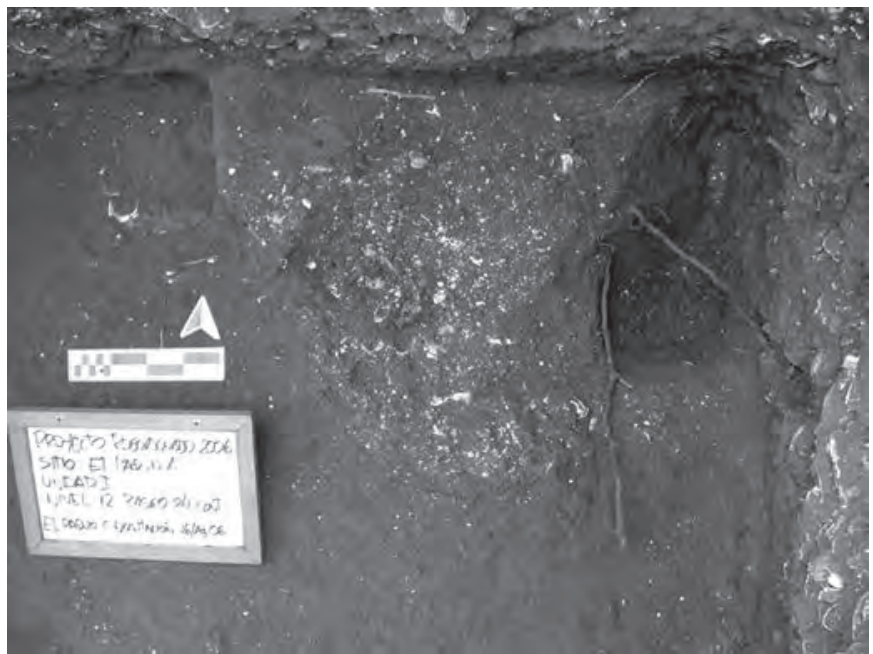

Figura 27. El Paquió. Unidad de Excavación 1, Nivel 12. Rasgo 4, Base de área de quema o fogón. Fotografía de Gori Echevarría, 2006.

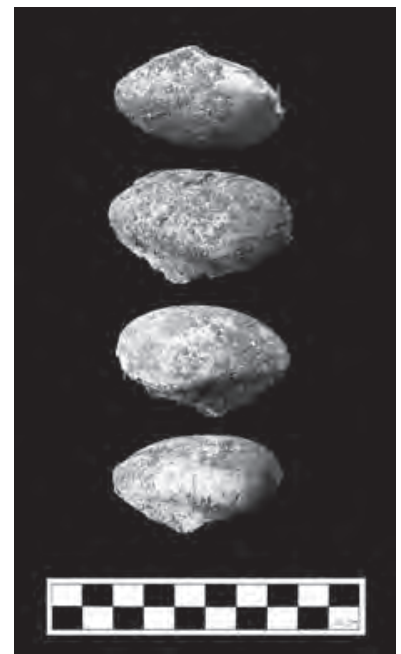

Figura 28. Conchas arqueológicas excavadas en el Paquió, corresponden a la especie Leila Blainvilliana. Fotografía de Gori Echevarría, 2006.

Lo que destaca también de la excavación es la documentación del cambio en el tipo de acumulación de desechos de este material, lo que estaría indicando una drástica modificación en los patrones de acumulación y procesamiento de este molusco. Dado el salto cuantitativo, este hecho debe estar vinculado al aprovechamiento probablemente comercial de este recurso, más que a algún tipo de presión poblacional específico.

Este pozo también reportó, herramientas de concha, huesos de animales, y una cantidad notable de cerámica decorada. Este último ítem aún no ha sido extensivamente analizado, pero es bastante claro que hay una integridad estilística desde las primeras etapas de formación del yacimiento. La característica es la decoración pintada precocción rojo/marrón sobre blanco o crema, dominado los motivos geométricos, lineales paralelos, y cruzados diagonalmente (Figs. 29 y 30). Otros motivos decorados, como los apéndices, incisiones, y algunas variaciones de pintura son mínimos y pueden considerarse intrusivos. Este yacimiento y en extenso los cuatro sitios excavados se caracterizan primariamente por su cerámica pintada, cerámica que es similar a la que excavó John Walker entre los ríos San Juan de Iruyañez y Omi (1999) y las reportadas por Tyuleneva (2007); y en menor medida con las muestras del Mojos central aunque con otros patrones decorativos y con componentes incisos más dominantes.

\section{CONCLUSIONES}

Es importante destacar que, hasta donde tenemos información, ninguno de los contextos arqueológicos excavados en los Llanos de Mojos presenta las características de formación que el Paquió posee, consistente en contextos de deposición muy específicos. Esto contrasta con las acumulaciones de 


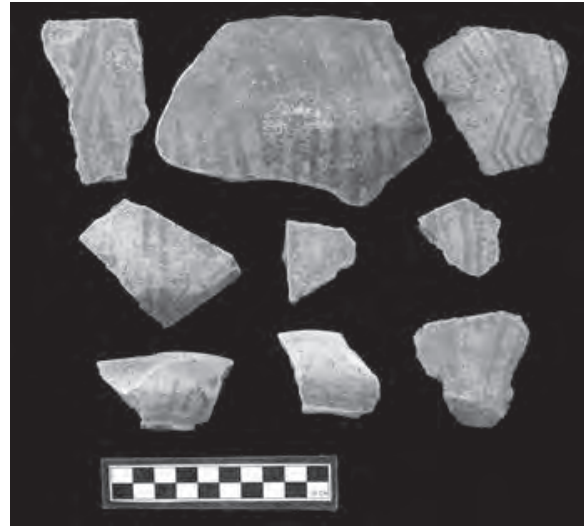

Figura 29. Cerámica pintada de El Paquió. Unidad 1, Nivel 2. Fotografía de Gori Echevarría, 2006.

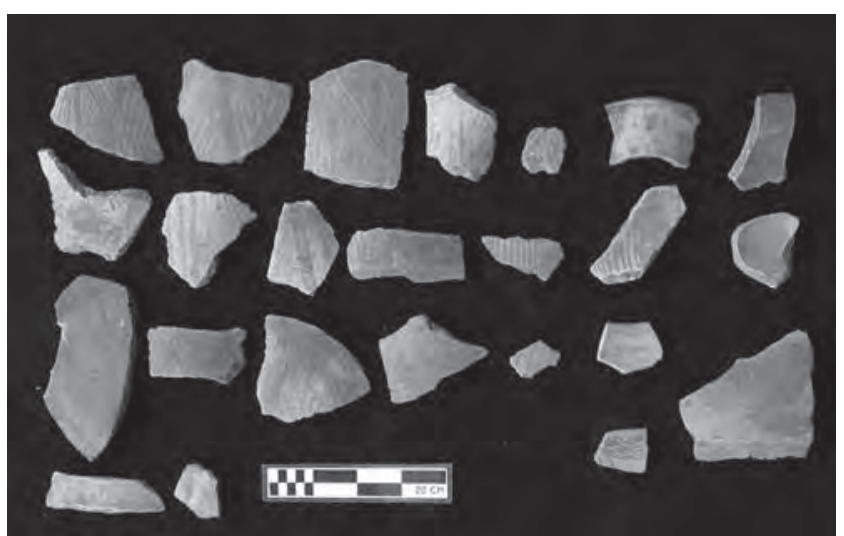

Figura 30. Cerámica pintada de El Paquió. Unidad 1, Nivel 2. Fotografía de Gori Echevarría, 2006.

tierra y fragmentos cerámicos inmersos con pocos contextos discretos definidos, y muy dependientes de los procesos medioambientales que la afectan. Este hecho hace del Paquió y en extenso de la zona de lago Rogoaguado, un área promisora para futuras investigaciones arqueológicas.

Lo que se ha expuesto aquí de manera resumida, es data nueva para la arqueología de los Llanos de Mojos, y esta incluye el componente cerámico, que también conforma un conjunto novedoso. Si la zona de Rogoaguado es el centro de la producción y distribución de cerámica pintada de al menos la parte norcentral de los Llanos de Mojos, lo cual debe investigarse aún más extensamente, no está demás reparar en la consideración de la nomenclatura y nosotros ya habíamos propuesto el nombre de «Coquinal» para el estilo cerámico en nuestro reporte a la Unidad Nacional de Arqueología de Bolivia el año 20085; no obstante, aún queda pendiente deslindar los componentes individuales de ensamblaje estilístico de nuestra colección, definir las correlaciones regionales respectivas y procurar ajustar la cronología de este material, y en general de todos los yacimientos, respecto a la región en conjunto ${ }^{6}$.

Por otro lado, debemos concluir que los yacimientos de Rogoaguado que hemos estudiado no están relacionados de modo alguno a las referencias históricas que se tiene para la zona. Ya sea para presencia de asentamientos relacionados al «Paititi», o para el grupo social que se conoce históricamente como Cayuvava; y esta conclusión es coincidente con los planteamientos de Dougherty y Calandra (1984) para la zona del Mojos Central, y de Walker (1999) para la zona de Iruyañez-Omi, al sureste de Rogoaguado.

En la arqueología de los Llanos de Mojos ha existido una tendencia a la uniformización de los patrones o modelos culturales y de organización social, especialmente desde los trabajos de Nordenskiöld y William Denevan; en la actualidad esta tendencia va siendo superada ampliamente, y hallazgos como el nuestro pueden ayudar a replantear los modelos o patrones regulares de población y supervivencia que aún se estiman para la zona y que jamás han considerado, por ejemplo, el usufructo lacustre del tipo que hemos evaluado. A pesar de esto, es claro que la caracterización adecuada, en un amplio sentido artefactual, de las ocupaciones precoloniales de los llanos de Mojos todavía se halla pendiente, y en la solución de esta tarea, todos los aportes son significativos.

5 Actualmente Unidad de Arqueología y Museos (UDAM).

6 Un estudio estilístico de la cerámica de El Paquió será publicada próximamente. 


\section{BiBLIOGRAFÍA}

ARELLANO, Jorge

1978 La arqueología de los Llanos del Beni y Bolivia. La Paz: INAR.

2002 Reconocimiento Arqueológico en la Cuenca del Río Orthon, Amazonia Boliviana. Quito: Museo Jacinto Jijón y Caamaño.

BUSTOS, Víctor

1976 Investigaciones arqueológicas en Trinidad, Departamento del Beni. La Paz: Instituto Nacional de Arqueología, Publicación No. 22.

1978 La arqueología de los Llanos del Beni, Bolivia. La Paz: Instituto Nacional de Arqueología, Documentos Internos no. 32/78.

CALANDRA, Horacio y Susana SALCEDA

2004 «Amazonia boliviana: arqueología de los Llanos de Mojos». Acta Amazónica 32(2): 155-163.

CUELLAR, Álvaro (ed.)

2003 Informe de desarrollo humano en el norte amazónico. La Paz: Programa de las Naciones Unidas para el Desarrollo PNUD, Plural Editores.

D'ORBIGNY, Alcides

1835-47 Voyage dans l'Amérique Méridionale (le Brésil, la république orientale de l'Uruguay, la République argentine, la Patagonie, la république du Chili, la république de Bolivia, la république du Pérou), exécuté pendant les années 1826, 1827, 1828, 1829, 1830, 1831, 1832, et 1833. Paris: Pitois-Levrault, et c.e; Strasbourg, V.e Levrault.

DENEVAN, William M.

1966 The Aboriginal Cultural Geography of The Llanos De Mojos Of Bolivia. Washington Dc: National Academy Of Sciences-National Research Council, Foreign Field Research Program No 24.

FERNÁNDEZ, Alicia

1987 «Informe sobre los hallazgos cerámicos superficiales en Eviato (Depto. Del Beni, Rep. De Bolivia). Scripta Etnológica 11: 141-152.

DOUGHERTY, Bernard y Horacio A. CALANDRA

1981 «Nota preliminar sobre investigaciones arqueológicas en los Llanos de Moxos, Departamento del Beni, República de Bolivia». Revista del Museo de La Plata VIII(53): 87-106. La Plata.

1981-1982 «Excavaciones arqueológicas en la Loma Alta de Casarabe, Llanos de Moxos, Departamento del Beni, Bolivia». Relaciones de la sociedad Argentina de Antropología XIV(2): 9-48. Buenos Aires.

1984 «Prehispanic human settlement in the Llanos of Moxos, Bolivia», En:Jorge Rabassa (ed.), Quaternary of South America and Antarctic Peninsula, Vol 2, pp. 163-169. A. A. Balkena Publishers, RotterdamBoston.

1984-1985 «Ambiente y arqueología en el oriente Boliviano: la Provincia de Iténez del Departamento del Beni». Relaciones de la sociedad Argentina de Antropología XVI: 37-61. Buenos Aires.

ECHEVARRIA, Gori

2008a Informe de Labores. Excavaciones arqueológicas en la cuenca del Lago Rogoaguado, Provincia de Yacuma, Beni, Bolivia. Temporada 2006. Presentado a la UNAR, La Paz.

2008 b «xcavaciones arqueológicas en la Cuenca del lago Rogoaguado, Provincia de Yacuma (Beni, Bolivia)». Estudios Amazónicos V(7): 87-150. Lima.

EDER, Francisco

1985 Breve descripción de las reducciones de Mojos (ca. 1772). J.M. Barnadas (Traducción y edición). Cochabamba: Historia Boliviana.

ERICKSON, Clark

1980 «Sistemas agrícolas prehispánicos en los Llanos de Mojos». América Indígena XL(4): 731-755. México D.F.

2000 «Lomas de ocupación en los Llanos de Moxos», En: Alicia Durán Coirolo y Roberto Bracco Boksar (eds.), Arqueología de Tierras Bajas, pp. 207-226. Comisión Nacional de Arqueología, Ministerio de Educación y Cultura, Montevideo. 
2006 «The domesticated landscapes of the Bolivian Amazon». En: Clark Erickson y William Balée (editors), Time and Complexity in Historical Ecology, pp. 235 - 278. Columbia University Press, New York.

2010 «The Transformation of Environment into Landscape: The Historical Ecology of Monumental Earthwork Construction in the Bolivian Amazon». Diversity 2: 618-652.

HAENKE, Tadeo

1796 Descripción Geográfica, Física e Histórica de las Montañas avitadas de la Nación de los Yndios Yuracarees, Carta al Virrey de Buenos Aires, Pedro Melo de Portugal, Cochabamba, 16 de Mayo.

HANKE, Wanda

1957 «Einige Fünde im Beni-Gibiet (Ostbolivien)», Archiv für Volkerkunde, Wien 12: 136-143.

JAIMES, Carla

2004 Secuencia cerámica del corte 1 de la Loma Mendoza. Tesis de Licenciacitura, Universidad Mayor de San Andrés, La Paz.

2010a La Cerámica De La Loma Salvatierra. Tesis de Doctorado, Universidad Mayor de San Andrés, La Paz.

2010b «Hecho en Mojos: mil años de alfarería en la Loma Salvatierra». XXIV Reunión Anual de Etnología, pp. 79-96. Museo Nacional de Etnografía y Folklore, La Paz.

2012 «La cerámica de dos montículos habitacionales». En: C. Isendahl (ed.), The Past Ahead. Languaje, Culture, and Identity in the Neotropics, pp. 161-184. Uppsala University, Uppsala.

KARWOWSKI, Andrzej; Marcin OBALEK y Mileniusz SPANOWICZ

2008 «Investigaciones Arqueológicas del sitio Uauauno, Departamento del Beni, Bolivia. Temporadas 2004 y 2005». En: J. K. Kozlowski y J. Zralka (eds.), Polish Contributions in New World Archaeology, New Series, fasc. 1, pp. 41-50. Polish Academy of Arts and Sciences, Jagiellonian University - Institute of Archaeology, Krakow.

KARWOWSKI, Andrzej

2008 «Investigaciones Arqueológicas del sitio Uauauno, Departamento del Beni, Bolivia». Tambo, Boletín de Arqueología 1: 131-141. Arequipa.

MANN, Charles C.

2008 «Earthmovers of the Amazon». Science 287(5454): 786-789.

METRAUX, Alfred

1942 The Native Tribes of Eastern Bolivia and Western Mato Grosso, Washington: Smithsonian Institution, Bureau of American Ethnology.

MICHEL, Marcos

1993 Prospección arqueológica de San Ignacio de Moxos, Provincia de Moxos, Departamento del Beni, Bolivia. Tesis de Licenciatura, Universidad Mayor de San Andrés.

NORDENSKIÖLD, Erland

1910 «Exploration ethnographique et Archeologique en Bolivie (1908-1909)», La Geographie. Revue mensuel de la Societé de Geographie XXII(2): 97-104. Paris.

1913 «Urnengraber und Mounds im Bolivianischen Flachland». Baessler Archiv 3: 205-255.

1924 The Ethnography of South America as seen from Mojos in Bolivia. Goteborg: Comparative Ethnological Studies III.

PORTUGAL, Max

1978 La arqueología de la región del Río Beni. La Paz: Ed. Casa Municipal de la Cultura «Franz Tamayo».

PRÜMERS, Heiko

2012 «El Proyecto Lomas de Casarabe: investigaciones arqueológicas». En Christian Isendahl (Ed.), The Past Ahead. Languaje, Culture, and Identity in the Neotropics, pp. 111-138. Uppsala: Uppsala University.

RECIO DE LEÓN, Juan

1906 «Relaciones y memoriales de... Teniente del Gobernador Pedro Laegui, sobre su entrada á las provincias de Tipuani, Chunchos y Paitity [1623-1627]» En: V.M. Maurtua (ed.) Juicio de Límites entre el Perú y Bolivia. Prueba Peruana Presentada al Gobierno de la República Argentina, Vol. VI, pp. 212-271 (Gobernaciones de Álvarez Maldonado y Laegui Urquiza), Barcelona. 
RYDEN, Stig

1941 A Study of the Sirionó Indians. Goteborg: Elanders Boktryckeri Aktiebolag.

1964 «Tripod Ceramics and Grater Bowls from Mojos, Bolivia», Beitrage zur Volkerkunde Sudamerikas, Festgabe fur Herbert Baldas zum 65, Geburtstag. Volkerkundliche Abhandlungen, Band 1, pp. 261-270, Hanover.

SANEMATSU, Katsuyoshi (Ed.)

2006 The Project Mojos 2005 Report. Informe del Proyecto Mojos 2005. Japan-Bolivia: Project Mojos.

STEWARD, Julian H. and Louis C. FARON

1959 Native Peoples of South America, New York: McGraw-Hill Book Company.

TYULENEVA, Vera

2007 «La tierra del Paititi y el lago Rogoaguado». Estudios Amazónicos IV(6): 97-154. Lima.

2010 Cuatro Viajes a la Amazonia Boliviana. Bolivia: Foro Boliviano sobre Medio Ambiente y Desarrollo.

VILLALBA, M. J., A. ALESÁN, M. COMAS, J. J. TRESSERRAS, J. A. LÓPEZ SÁEZ, A. MALGOSA, M. MICHEL y R. PLAYÀ

2004 Investigaciones arqueológicas en los Llanos de Moxos (Amazonía boliviana). Una aproximación al estudio de los sistemas de producción precolombinos. Bienes Culturales: Revista del Instituto de Patrimonio Histórico Español 3: 201-215.

WALKER, John

1999 Agricultural Change in the Bolivian Amazon. Dissertation for the Degree of Doctor of Philosophy, University of Pensilvania, USA.

2011 «Ceramic assemblages and landscape in the mid-1st millennium Llanos de Mojos, Beni, Bolivia». Journal of Field Archaeology 36.2: 119-131. 